\title{
Sb-related defects in Sb-doped ZnO thin film grown by pulsed laser deposition
}

Cite as: J. Appl. Phys. 123, 161525 (2018); https://doi.org/10.1063/1.4997510

Submitted: 25 July 2017 . Accepted: 18 October 2017 . Published Online: 03 November 2017

Caiqin Luo, Lok-Ping Ho $(\mathbb{D})$, Fahad Azad, Wolfgang Anwand, Maik Butterling, Andreas Wagner (D), Andrej Kuznetsov, Hai Zhu, Shichen Su, and Francis Chi-Chung Ling (D)
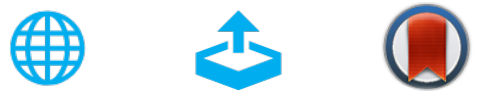

View Online

Export Citation

\section{ARTICLES YOU MAY BE INTERESTED IN}

Defect induced room temperature ferromagnetism in single crystal, poly-crystal, and nanorod ZnO: A comparative study

Journal of Applied Physics 123, 161507 (2018); https://doi.org/10.1063/1.4986606

Identification of F impurities in F-doped ZnO by synchrotron X-ray absorption near edge structures

Journal of Applied Physics 123, 161528 (2018); https://doi.org/10.1063/1.4997356

A comprehensive review of $\mathrm{ZnO}$ materials and devices

Journal of Applied Physics 98, 041301 (2005); https://doi.org/10.1063/1.1992666

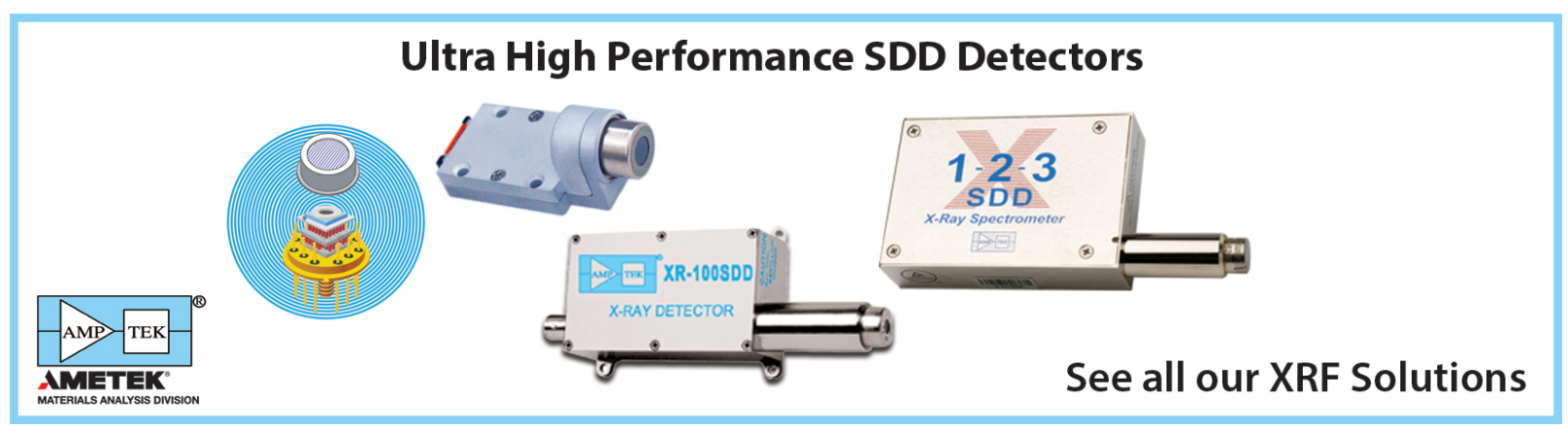




\title{
Sb-related defects in Sb-doped $\mathrm{ZnO}$ thin film grown by pulsed laser deposition
}

\author{
Caiqin Luo, ${ }^{1}$ Lok-Ping Ho, ${ }^{1}$ Fahad Azad, ${ }^{1}$ Wolfgang Anwand, ${ }^{2}$ Maik Butterling, ${ }^{2}$ \\ Andreas Wagner, ${ }^{2}$ Andrej Kuznetsov, ${ }^{3}$ Hai Zhu, ${ }^{4}$ Shichen Su, ${ }^{1,5}$ \\ and Francis Chi-Chung Ling ${ }^{1, a)}$ \\ ${ }^{1}$ Department of Physics, The University of Hong Kong, Hong Kong, China \\ ${ }^{2}$ Institute of Radiation Physics, Helmholtz-Zentrum Dresden-Rossendorf, Dresden, Germany \\ ${ }^{3}$ Department of Physics, Oslo University, Oslo, Norway \\ ${ }^{4}$ State Key Laboratory of Optoelectronic Materials and Technologies, School of Physics, Sun Yat-Sen \\ University, Guangzhou, China \\ ${ }^{5}$ Institute of Optoelectronic Material and Technology, South China Normal University, Guangzhou, China
}

(Received 25 July 2017; accepted 18 October 2017; published online 3 November 2017)

\begin{abstract}
Sb-doped $\mathrm{ZnO}$ films were fabricated on c-plane sapphire using the pulsed laser deposition method and characterized by Hall effect measurement, X-ray photoelectron spectroscopy, X-ray diffraction, photoluminescence, and positron annihilation spectroscopy. Systematic studies on the growth conditions with different $\mathrm{Sb}$ composition, oxygen pressure, and post-growth annealing were conducted. If the $\mathrm{Sb}$ doping concentration is lower than the threshold $\sim 8 \times 10^{20} \mathrm{~cm}^{-3}$, the as-grown films grown with an appropriate oxygen pressure could be $\mathrm{n} \sim 4 \times 10^{20} \mathrm{~cm}^{-3}$. The shallow donor was attributed to the $\mathrm{Sb}_{\mathrm{Zn}}$ related defect. Annealing these samples led to the formation of the $\mathrm{Sb}_{\mathrm{Zn}}-2 \mathrm{~V}_{\mathrm{Zn}}$ shallow acceptor which subsequently compensated for the free carrier. For samples with $\mathrm{Sb}$ concentration exceeding the threshold, the yielded as-grown samples were highly resistive. Xray diffraction results showed that the $\mathrm{Sb}$ dopant occupied the $\mathrm{O}$ site rather than the $\mathrm{Zn}$ site as the $\mathrm{Sb}$ doping exceeded the threshold, whereas the $\mathrm{Sb}_{\mathrm{O}}$ related deep acceptor was responsible for the high resistivity of the samples. Published by AIP Publishing. https://doi.org/10.1063/1.4997510
\end{abstract}

\section{INTRODUCTION}

$\mathrm{ZnO}$, having a direct wide band gap of $3.4 \mathrm{eV}$ and a large exciton energy of $60 \mathrm{meV}$, has received extensive attention because of its potential in a variety of applications including ultra-violet (UV) optoelectronics, transparent electronics, sensors, spintronics, etc. ${ }^{1}$ Despite extensive efforts, the development of practical ZnO-based devices was deterred by the difficulty in achieving p-type doping. ${ }^{2-4}$ Undoped $\mathrm{ZnO}$ materials are usually n-type in conductivity and degenerately n-type doping is easily obtained using dopants like $\mathrm{Ga}$ or $\mathrm{Al}$. Hydrogen, intrinsic defects, and $\mathrm{OH}$ and their defect complexes ${ }^{5-9}$ have also been suggested to be the shallow donors in $\mathrm{ZnO}$ materials. Group $\mathrm{V}$ elements being $\mathrm{p}$ type dopants of $\mathrm{ZnO}$ have already been studied intensively. ${ }^{1,10-13}$ With first principles calculation, Limijumnong et $a l .{ }^{14}$ showed that the Zn-substitutional defects $\mathrm{X}_{\mathrm{Zn}}(\mathrm{X}=\mathrm{P}$, As and $\mathrm{Sb}$ ) were donors, and the $\mathrm{O}$-substitutional defects $\mathrm{X}_{\mathrm{O}}$ were deep acceptors. Because of the large size mismatch, theoretical calculation showed that $\mathrm{X}_{\mathrm{Zn}}$ had lower formation energy than $\mathrm{X}_{\mathrm{O}}$. Moreover, the $\mathrm{X}_{\mathrm{Zn}}-2 \mathrm{~V}_{\mathrm{Zn}}$ defect complexes $(\mathrm{X}=\mathrm{P}, \mathrm{As}$, and $\mathrm{Sb})$ are a shallow acceptor with low formation energies. ${ }^{14}$ An experimental study of conversion-electron emission channeling from the implanting radioactive ${ }^{73}$ As confirmed that the majority of the implanted As is located at the $\mathrm{Zn}$-site ${ }^{15}$ and a similar result was also observed for $\mathrm{Sb} .^{16}$ There were also experimental studies reporting the fabrication of p-type $\mathrm{ZnO}$ using these dopants (for example, Refs. 17-21).

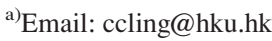

However, the p-type conductivity was not reliable. There were also disagreements on the formation of $\mathrm{X}_{\mathrm{Zn}}-2 \mathrm{~V}_{\mathrm{Zn}}$ in $\mathrm{ZnO}$. Janotti and Van de Walle ${ }^{22}$ argued that the formation of these defect complexes was unlikely from the energetic consideration and the entropic considerations for the formation of complexes comprising of three constituents. With $a b$ initio calculation, Puchaia and Morgan ${ }^{23}$ reported that $\mathrm{X}_{\mathrm{i}}-3 \mathrm{~V}_{\mathrm{Zn}}$ (i.e., the $\mathrm{X}$ interstitial surrounded by three $\mathrm{V}_{\mathrm{Zn}}$ ) was the most stable Group V dopant-vacancy complex in ZnO. It was a deep acceptor and could not contribute to the p-type conductivity.

In the present study, Sb-doped $\mathrm{ZnO}$ films were grown on c-plane sapphire by pulsed laser deposition (PLD). The asgrown $\mathrm{Sb}$-doped $\mathrm{ZnO}$ samples were degenerately $\mathrm{n}^{+}$-type having $n>10^{20} \mathrm{~cm}^{-3}$, and annealing at $750{ }^{\circ} \mathrm{C}$ lead to a dramatic decrease of the carrier concentration to $<10^{15} \mathrm{~cm}^{-3}$. A comprehensive spectroscopic study including Hall effect measurements, X-ray photoelectron spectroscopy (XPS), X-ray diffraction (XRD), and positron annihilation spectroscopy (PAS) was performed with an attempt to understand the correlations between the defects and the carrier concentrations.

\section{EXPERIMENTAL}

The undoped $\mathrm{ZnO}$ and $\mathrm{Sb}$-doped $\mathrm{ZnO}$ thin films were grown on the c-plane sapphire substrate using the pulsed laser deposition (PLD) method. The target was $\mathrm{ZnO}: \mathrm{Sb}_{2} \mathrm{O}_{3}$ with different $\mathrm{Sb}$ weight ratios of $0.5 \%, 1 \%, 2 \%$, and $3 \%$. The background pressure was $\sim 10^{-4} \mathrm{~Pa}$. An excited $\mathrm{KrF}$ excimer laser (wavelength $=248 \mathrm{~nm}$, a pulse energy of $300 \mathrm{~mJ}$, and frequency $=2 \mathrm{~Hz}$ ) was employed to ablate the target. During 
the growth, the substrate temperature was kept at $350{ }^{\circ} \mathrm{C}$, and two oxygen pressures were adopted $\left(\mathrm{P}\left(\mathrm{O}_{2}\right)=1.3\right.$ and $\left.5 \mathrm{~Pa}\right)$ during the growth. The thickness of the film was about $300 \mathrm{~nm}$. Isochronal annealing was performed in a tube furnace for $40 \mathrm{~min}$ in argon at 600,750 , and $900^{\circ} \mathrm{C}$, respectively. The sample was put into the furnace after the temperature was stable at the desired value. The ramp down rate was around $8{ }^{\circ} \mathrm{C} / \mathrm{min}$. The XRD study was conducted by using a Phillips D5000 and Bruker D8 advance (high resolution) $\mathrm{X}$-ray diffractometer with the $\mathrm{Cu} \mathrm{K} \alpha$ line. The Hall measurement was conducted at room temperature using the van der Pauw configuration by the Accenet HL-5500PC system. The XPS measurements were carried out by using the VG MICROTECH MT500 XPS system. For the SIMS measurement, the IONTOF TOF-SIMS V spectrometer was used. PAS measurement was carried out with a $35 \mathrm{keV}$ mono-energetic positron beam. A high purity Ge detector and the corresponding nuclear electronics which had an energy resolution of $1.1 \mathrm{keV}$ for the $514 \mathrm{keV}$ line were used to collect the gamma ray energy spectra of the annihilation gamma photons. The window for obtaining the $\mathrm{S}$ parameter was $(511 \pm 0.92) \mathrm{keV}$.

\section{RESULTS}

\section{A. Structural characterization}

Figure 1 shows the diffraction patterns of the as-grown undoped $\mathrm{ZnO}$ and the $\mathrm{ZnO}: \mathrm{Sb}$ samples with $\mathrm{Sb}=1 \%, 2 \%$, and $3 \%$ obtained from the HRXRD measurements with the intensity plotted in the log scale. The major peaks found in all these spectra are the (002) and (004) peaks, and other three peaks (100), (101), (103), and (200) having negligibly small intensities $(\sim 100$ times less than that of the $(002)$ peak) were also identified. It is also noticed that no extra

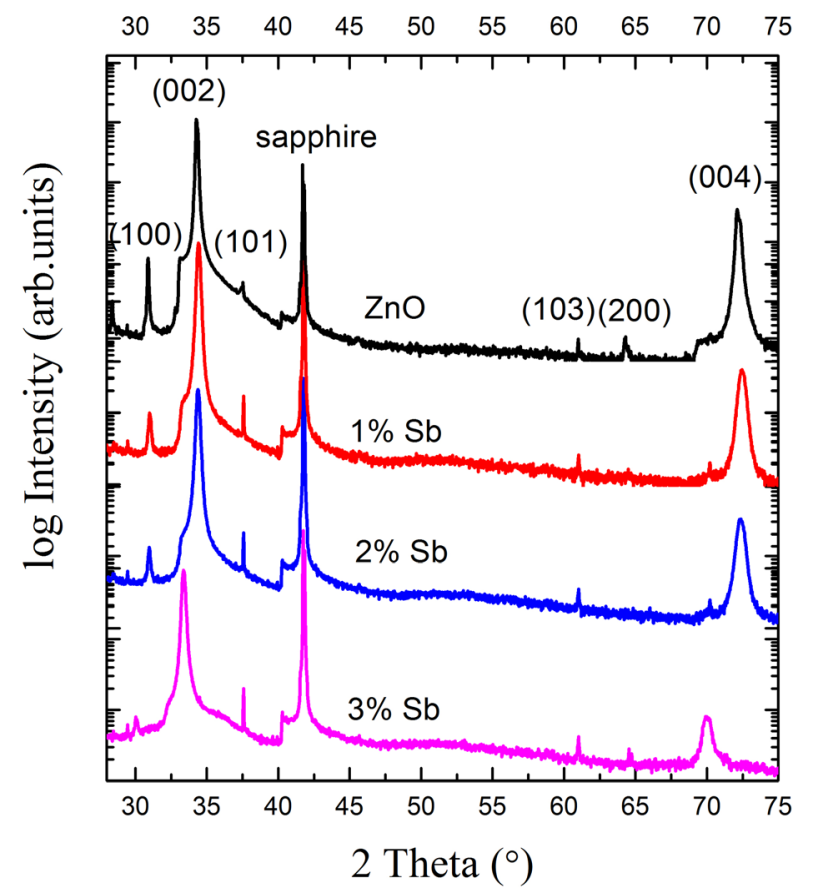

FIG. 1. The HRXRD spectra of the as-grown undoped and $\mathrm{ZnO}$ :Sb samples grown with $\mathrm{P}\left(\mathrm{O}_{2}\right)=1.3 \mathrm{~Pa}$. peaks in the Sb-doped $\mathrm{ZnO}$ spectra other than those identified in the undoped $\mathrm{ZnO}$ spectrum were found. All these results show that the films have a wurtzite structure orientated along the c-axis without any significant formation of $\mathrm{Sb}$ phases within the spectrometer resolution. Moreover, (002) and (004) peaks shifting to a low angle is observed for the $\mathrm{Sb}$-doped $\mathrm{ZnO}$ sample with $\mathrm{Sb}=3 \%$. This observation will be discussed in the upcoming paragraphs. Figure 2 shows the XRD spectra of the $\mathrm{Sb}$-doped $\mathrm{ZnO}$ samples grown with the oxygen pressure $\mathrm{P}\left(\mathrm{O}_{2}\right)=1.3 \mathrm{~Pa}$ with different postgrowth annealing treatments (namely, as-grown, 600, 750 and $900^{\circ} \mathrm{C}$ ). The magnified (002) peaks are also shown in the inset of the figure. New phase was not found in the XRD spectra during the annealing process. The (002) peaks shift to a low angle for the samples annealed at 750 and $900{ }^{\circ} \mathrm{C}$ and this will be discussed later.

The full width half maximum (FWHM) of the (002) peaks for the different $\mathrm{ZnO}: \mathrm{Sb}$ samples grown with $\mathrm{P}\left(\mathrm{O}_{2}\right)$ $=1.3 \mathrm{~Pa}$ is shown in Fig. 3(a). The FWHM of the as-grown $\mathrm{ZnO}: \mathrm{Sb}$ samples increases slightly from $0.241^{\circ}$ to $0.244^{\circ}$ as the $\mathrm{Sb}$ composition increases from $1 \%$ to $2 \%$, and then an abrupt increase is observed as the $\mathrm{Sb}$ composition further increases to $3 \%$, implying the deterioration of the crystalline quality by high level $\mathrm{Sb}$ doping. An annealing study on the samples with a $\mathrm{Sb}$ composition of $2 \%$ shows that an abrupt decrease of FWHM is induced by annealing at $750{ }^{\circ} \mathrm{C}$, which is possibly associated with the improvement in the crystalline quality. The lattice constants of the samples were also calculated and the results are shown in Fig. 3(b). The lattice constants of the as-grown Sb-doped $\mathrm{ZnO}$ films doped with $1 \%$ and $2 \% \mathrm{Sb}$ are the same as $5.21 \AA$. A dramatic increase

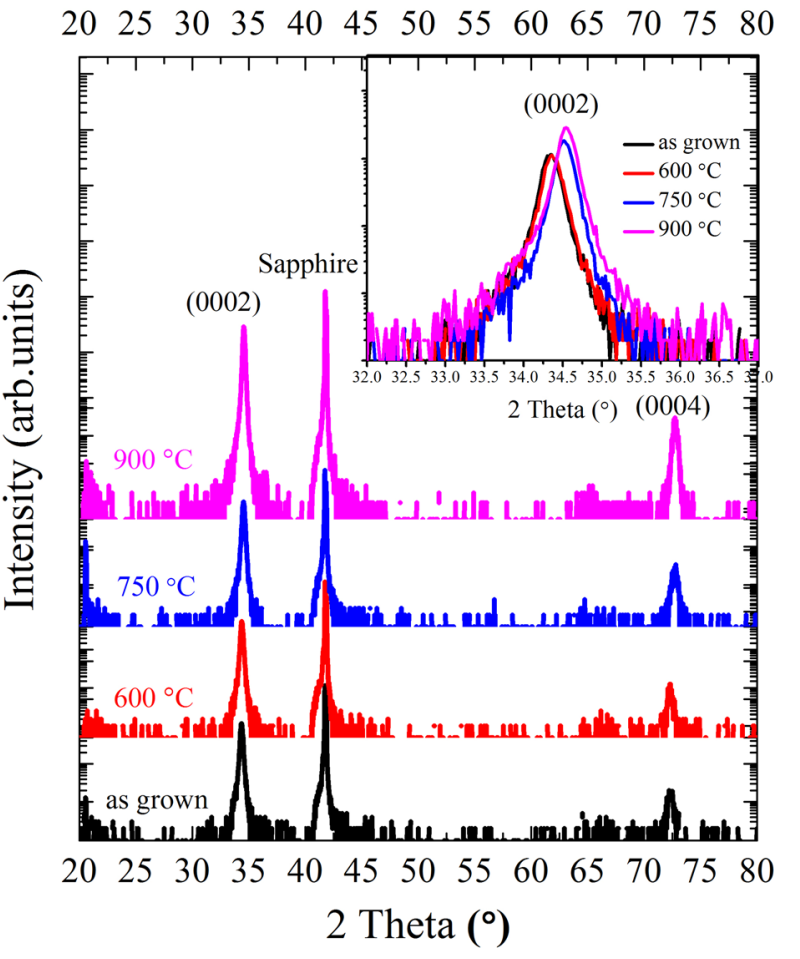

FIG. 2. The XRD spectra of the $\mathrm{Sb}$ doped $\mathrm{ZnO}$ thin films grown on sapphire annealed at different temperatures. The inset shows the magnified (002) peaks of the spectra. The PLD growths were performed with the oxygen pressure of $1.3 \mathrm{~Pa}$. 


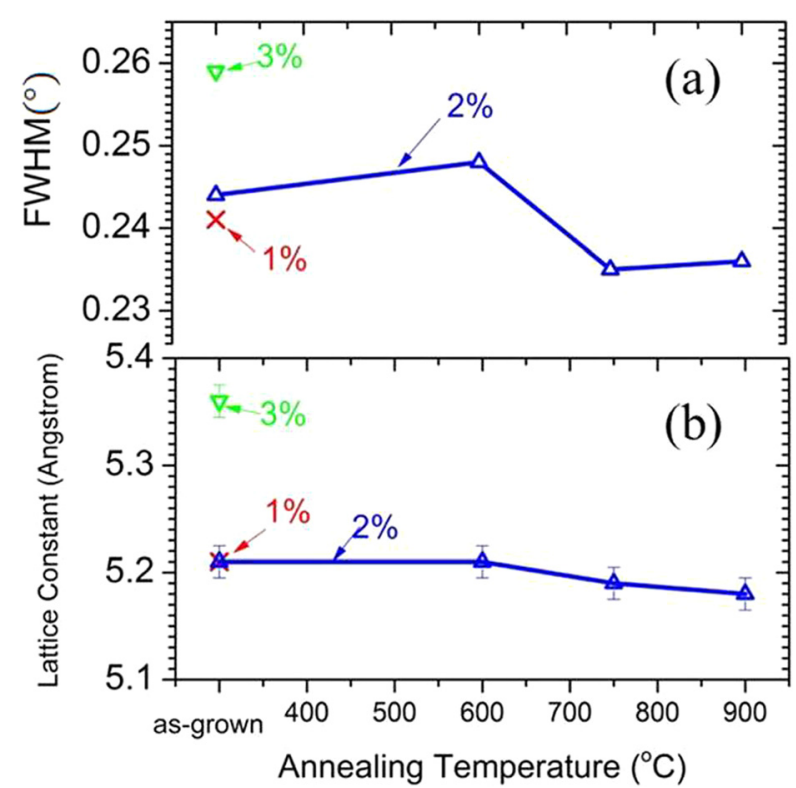

FIG. 3. (a) The FWHM of the $\mathrm{ZnO}(002)$ peaks in the XRD spectra and (b) the lattice constant for the $\mathrm{ZnO}: \mathrm{Sb}(2 \%)$ samples as a function of the annealing temperature. The corresponding FWHM's and lattice constant for the asgrown $\mathrm{ZnO}: \mathrm{Sb}$ samples with $\mathrm{Sb}$ compositions of $1 \%$ and $3 \%$ were also included. All the samples were grown with the oxygen pressure of $1.3 \mathrm{~Pa}$.

of the lattice constant to $5.36 \AA$ was observed as the $\mathrm{Sb}$ composition further increased to $3 \%$. The effect of annealing on the lattice constant was shown for the case of Sb composition equal to $2 \%$. A very slight decrease of the lattice constant (though within the measurement error) from $5.21 \AA$ to $5.18 \AA$ occurred after annealing at $750^{\circ} \mathrm{C}$.

SIMS measurement was carried out to obtain the depth profile of $\mathrm{Sb}$ for the $\mathrm{ZnO}: \mathrm{Sb}(2 \%)$ sample grown with $\mathrm{P}\left(\mathrm{O}_{2}\right)$ $=1.3 \mathrm{~Pa}$ in the as-grown state and that annealed at $900^{\circ} \mathrm{C}$. The SIMS depth profiles showed a rather uniform distribution of Sb throughout the whole film, and no segregation was observed. The atomic concentration of $\mathrm{Sb}$ in the $\mathrm{ZnO}: \mathrm{Sb}$ samples grown with the different $\mathrm{Sb}$ compositions in the target (by weight) was measured by XPS, and the results are plotted in Fig. 4. The $\mathrm{Sb}$ concentration of the as-grown

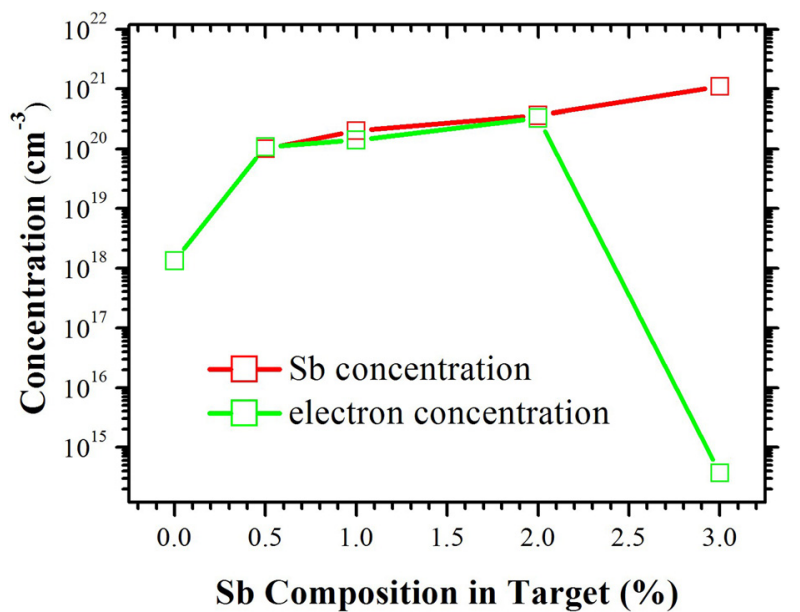

FIG. 4. The electron concentration and $\mathrm{Sb}$ concentration measured by Hall measurement and XPS, respectively, are plotted against the Sb composition (in weight) of the target used for the PLD growth.
Sb-doped sample increased linearly with the Sb composition in the target, from $1 \times 10^{20} \mathrm{~cm}^{-3}$ to $1 \times 10^{21} \mathrm{~cm}^{-3}$, as the $\mathrm{Sb}$ composition increased from $0.5 \%$ to $3 \%$.

\section{B. Hall measurements}

Hall measurements showed that all the Sb-doped $\mathrm{ZnO}$ samples exhibited n-type conductivity. Figure 4 shows the electron concentration as a function of the $\mathrm{Sb}$ composition (by weight in the target) for the as-grown $\mathrm{Sb}$-doped $\mathrm{ZnO}$ samples grown with $\mathrm{P}\left(\mathrm{O}_{2}\right)=1.3 \mathrm{~Pa}$. For the undoped $\mathrm{ZnO}$ sample, the electron concentration was $\sim 1 \times 10^{18} \mathrm{~cm}^{-3}$. With the $\mathrm{Sb}$ composition $\leq 2 \%$, doping more $\mathrm{Sb}$ had the effect of increasing the electron concentration and its value was effectively equal to the $\mathrm{Sb}$ concentration, i.e., increasing from $1 \times 10^{20} \mathrm{~cm}^{-3}$ to $3 \times 10^{20} \mathrm{~cm}^{-3}$, while the $\mathrm{Sb}$ composition increased from $0.5 \%$ to $2 \%$. This strongly suggests that the shallow donor is related to the Sb dopant. However, further increasing the $\mathrm{Sb}$ composition to $3 \%$ dramatically decreased the electron concentration to $\sim 4 \times 10^{14} \mathrm{~cm}^{-3}$ and the sample became highly resistive, though the concentrations of $\mathrm{Sb}$ increased to $1 \times 10^{21} \mathrm{~cm}^{-3}$. The dramatic drop in electron concentration could be due to formation of a compensation defect and/or the change of the Sb-related shallow donor microstructure as the $\mathrm{Sb}$ composition is high.

Figure 5 shows the electron concentration as a function of the oxygen pressure during growth $\mathrm{P}\left(\mathrm{O}_{2}\right)$ for the as-grown $\mathrm{ZnO}: \mathrm{Sb}(1 \%)$ sample. For the sample grown with no oxygen, the carrier concentration was $\sim 5 \times 10^{20} \mathrm{~cm}^{-3}$. Increasing $\mathrm{P}$ $\left(\mathrm{O}_{2}\right)$ had the effect of decreasing the electron concentration. As $\mathrm{P}\left(\mathrm{O}_{2}\right)$ reached $1.3 \mathrm{~Pa}$, the electron concentration decreased to the saturated value of $\sim 9 \times 10^{19} \mathrm{~cm}^{-3}$.

Figures 6(a) and 6(b) show the electron concentration as a function of the annealing temperature, respectively, for the undoped $\mathrm{ZnO}$, as well as the $\mathrm{ZnO}: \mathrm{Sb}(2 \%)$ samples grown with the growth oxygen pressures $\mathrm{P}\left(\mathrm{O}_{2}\right)=1.3$ and $5 \mathrm{~Pa}$. For the Sb-doped samples, the as-grown samples were n-type conducting and had carrier concentrations of $4 \times 10^{20} \mathrm{~cm}^{-3}$ and $1 \times 10^{19} \mathrm{~cm}^{-3}$ for the samples grown with $\mathrm{P}\left(\mathrm{O}_{2}\right)=1.3$ and $5 \mathrm{~Pa}$, respectively, which were significantly higher than those of the undoped samples. The two Sb-doped $\mathrm{ZnO}$ samples grown with the different $\mathrm{P}\left(\mathrm{O}_{2}\right)$ showed similar features. After annealing at $750{ }^{\circ} \mathrm{C}$, the electron concentrations of the

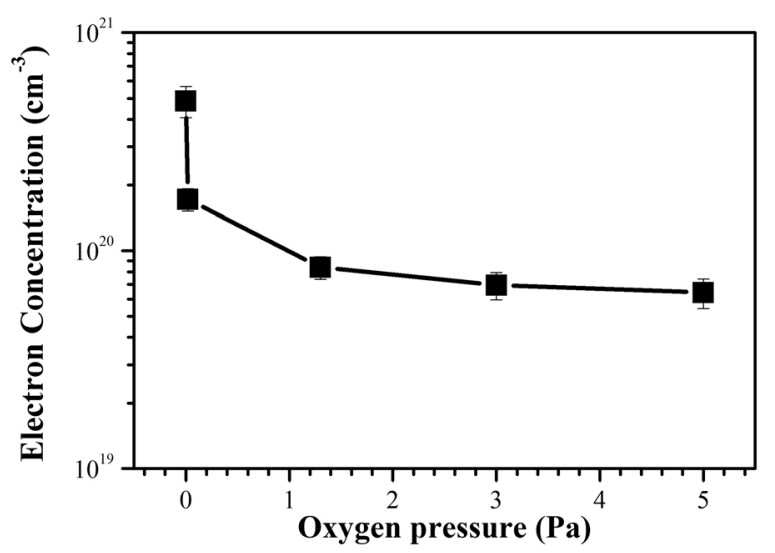

FIG. 5. The electron concentration of the as-grown $\mathrm{ZnO}: \mathrm{Sb}(1 \%)$ sample as a function of the oxygen pressure during growth. 


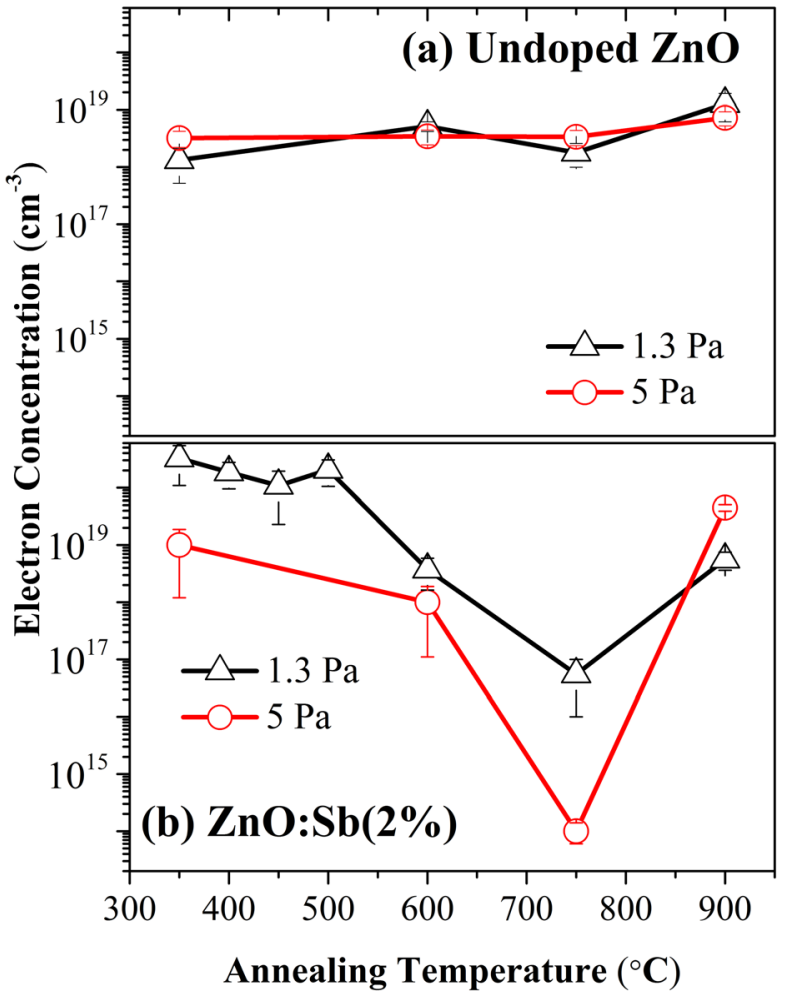

FIG. 6. The electron concentration as a function of the annealed temperature for (a) undoped $\mathrm{ZnO}$ samples and (b) $\mathrm{Sb}$-doped $\mathrm{ZnO}$ ( $\mathrm{Sb}=2 \%$ by weight) samples grown on the sapphire using the PLD method. The films were grown with oxygen pressures of 1.3 and $5 \mathrm{~Pa}$, respectively.

Sb-doped samples grown with $\mathrm{P}\left(\mathrm{O}_{2}\right)=1.3$ and $5 \mathrm{~Pa}$ dropped significantly to values of $\sim 10^{17} \mathrm{~cm}^{-3}$ and $\sim 10^{14} \mathrm{~cm}^{-3}$, respectively, corresponding to the decreasing of factors of 4000 and $10^{5}$. For the undoped samples, the electron concentration remained in a narrow range from $10^{18}$ to $10^{19} \mathrm{~cm}^{-3}$ irrespective of the $\mathrm{P}\left(\mathrm{O}_{2}\right)$ and the annealing temperature up to $900{ }^{\circ} \mathrm{C}$. This implies the abrupt thermally induced decrease in the carrier concentration as observed in the Sbdoped $\mathrm{ZnO}$ samples associated with the physics or chemistry of the $\mathrm{Sb}$ dopant.

Temperature dependent Hall measurements were performed on the as-grown $\mathrm{Sb}$-doped $\mathrm{ZnO}(\mathrm{Sb}=2 \%)$ sample grown with $\mathrm{P}\left(\mathrm{O}_{2}\right)=1.3 \mathrm{~Pa}$ at temperature ranging from $10 \mathrm{~K}$ to $300 \mathrm{~K}$, and the carrier concentration against the temperature data is shown in Fig. 7. At $\mathrm{T}=10 \mathrm{~K}$, the electron concentration was $\sim 2 \times 10^{19} \mathrm{~cm}^{-3}$. Increasing the temperature led to more shallow donors being ionized and thus resulted in the increase of the electron concentration. As the temperature increased to $\sim 150 \mathrm{~K}$, the electron concentration saturated at $\sim 2 \times 10^{20} \mathrm{~cm}^{-3}$ as a majority of the shallow donors became ionized. The ionization energy of the shallow donor was estimated by fitting the Arrhenius plot of the electron concentration in the temperature range of $10 \mathrm{~K}$ to $150 \mathrm{~K}$ (shown in the inset of Fig. 7), which yielded the result of $5.4 \pm 0.12 \mathrm{meV}$.

Figure 8 shows the measured electron mobility as a function of temperature for the $\mathrm{Sb}$-doped (2\%) $\mathrm{ZnO}$ sample grown with $\mathrm{P}\left(\mathrm{O}_{2}\right)=1.3 \mathrm{~Pa}$. Look et al. ${ }^{24}$ have developed a formalism to determine the donor and acceptor concentrations $\left(\mathrm{N}_{\mathrm{D}}\right.$ and $\mathrm{N}_{\mathrm{A}}$, respectively) from the mobility data in a degenerate

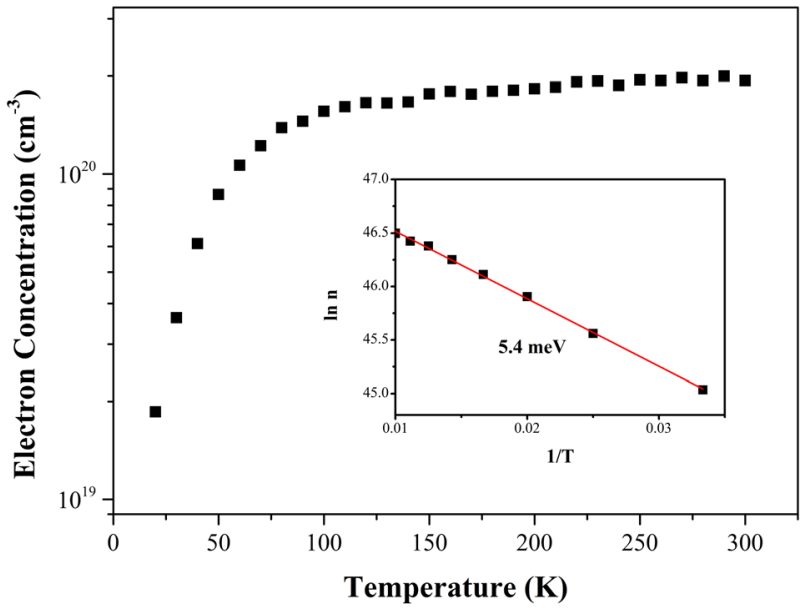

FIG. 7. The electron concentration against the temperature for the as-grown $\mathrm{Sb}$-doped sample $(\mathrm{Sb}=2 \%)$ grown with the oxygen pressure of $1.3 \mathrm{~Pa}$. The inset shows the corresponding Arrhenius plot at temperatures from $10 \mathrm{~K}$ to $150 \mathrm{~K}$, and the fitted straight yielding the ionization energy of the shallow donor.

semiconductor thin film system. The mobility is limited by ionized impurity scattering (ii), phonon scattering (ph), and charged grain boundary (bdry), and the total mobility is given by Matthiessen's rule $\mu_{\mathrm{tot}}{ }^{-1}=\mu_{\mathrm{ii}}{ }^{-1}+\mu_{\mathrm{ph}}{ }^{-1}+\mu_{\mathrm{bdry}}{ }^{-1}$. The mobility limited by ionized impurity scattering is given by ${ }^{25}$

$$
\begin{gathered}
\mu_{\mathrm{ii}}\left(\mathrm{n}, \mathrm{N}_{\mathrm{ii}}\right)=\mu_{\mathrm{ii} 0}(\mathrm{n}) \mathrm{n} / \mathrm{Z}^{2} \mathrm{~N}_{\mathrm{ii}}, \\
\mu_{\mathrm{ii} 0}(\mathrm{n})=\frac{24 \pi^{3} \varepsilon_{0}^{2} \hbar^{3}}{\mathrm{e}^{3} \mathrm{~m}^{* 2}} \frac{1}{\ln [1+\mathrm{y}(\mathrm{n})]-\frac{\mathrm{y}(\mathrm{n})}{1+\mathrm{y}(\mathrm{n})}},
\end{gathered}
$$

where $\mathrm{y}(\mathrm{n})=\frac{3^{1 / 3} 4 \pi^{8 / 3} \varepsilon_{0} \hbar^{2} \mathrm{n}^{1 / 3}}{\mathrm{e}^{2} \mathrm{~m}^{*}} \cdot \varepsilon_{0}$ is the static dielectric constant, $\hbar$ is the Planck's constant divided by $2 \pi . \mathrm{m}^{*}$, e is the effective mass and charge of the electron, respectively, $\mathrm{N}_{\mathrm{ii}}$ is the concentration of the ionized impurity having the charge of $\mathrm{Z}$, and $\mathrm{n}$ is the electron concentration of the sample.

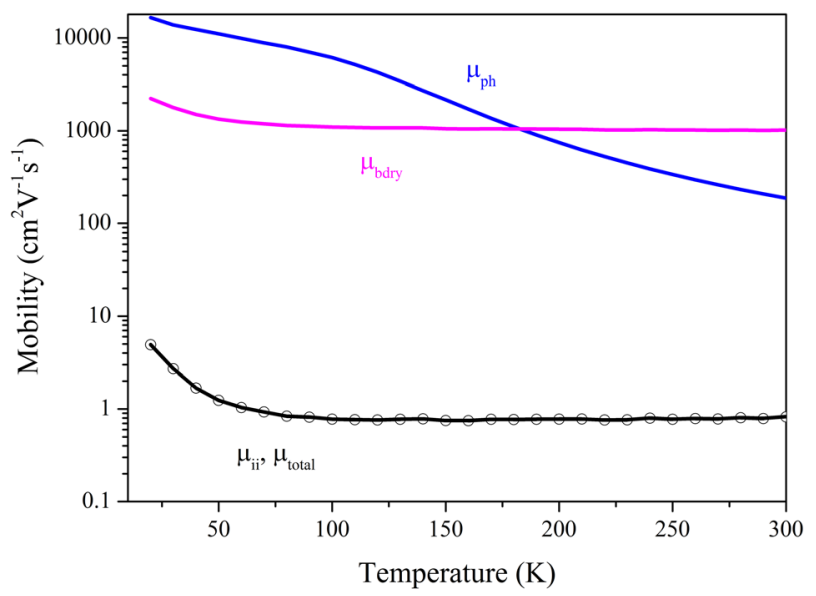

FIG. 8. Experimental mobility of the as-grown $\mathrm{ZnO}: \mathrm{Sb}(2 \%)$ sample (dots) as a function of the temperature. The simulated curves are the mobilities limited by phonon scattering $\mu_{p h}$, boundary scattering $\mu_{b d r y}$, ionizied impurity $\mu_{i i}$, and the total mobility calculated by the Matthiessen's rule $\mu_{\text {total }}$. Notice that the curves of $\mu_{i i}$ and $\mu_{\text {total }}$ are effectively the same. 

by $^{26}$

The optical phonon scattering limited mobility is given

$$
\mu_{\mathrm{po}}(\mathrm{T})=\frac{2^{\frac{3}{2}} \pi \hbar^{2}\left(\exp \left[\frac{T_{p o}}{T}\right]-1\right) \chi\left(\mathrm{T}_{\mathrm{po}} / \mathrm{T}\right)}{\mathrm{e}\left(\mathrm{kT}_{\mathrm{po}}\right)^{\frac{1}{2}}\left(\mathrm{~m}^{*}\right)^{\frac{3}{2}}\left(\varepsilon_{1}^{-1}-\varepsilon_{0}^{-1}\right)},
$$

where $\mathrm{T}_{\mathrm{po}}$ is the polar-optical temperature, $\mathrm{k}$ is the Boltzmann's constant, $\mathrm{T}$ is the measured temperature, and $\varepsilon_{1}$ is the high frequency dielectric constant. For $\mathrm{ZnO}$ at $\mathrm{T} \approx 0-300$ $\mathrm{K}, \chi\left(\mathrm{T}_{\mathrm{po}} / \mathrm{T}\right)=\left[1+\exp \left(-0.6 \mathrm{~T}_{\mathrm{po}} / \mathrm{T}\right)\right]^{-1}$. The expression of acoustic phonon scattering limited mobility is given by ${ }^{22}$

$$
\mu_{\mathrm{ac}}(\mathrm{n}, \mathrm{T})=\frac{\pi \hbar^{4} \mathrm{c}_{\mathrm{l}}}{2^{\frac{1}{2}}\left(\mathrm{~m}^{*}\right)^{\frac{5}{2}} \mathrm{E}_{1}^{2} \mathrm{ekT}} \mathrm{E}_{\mathrm{f}}(\mathrm{n})^{-1 / 2},
$$

where $c_{1}$ and $E_{1}$ are the longitudinal elastic constant and acoustic deformation potential, respectively. $E_{f}(n)$ is the Fermi-energy, which is given by $E_{f}(n)=\hbar^{2}\left(3 \pi^{2} n\right)^{2 / 3} / 2 m^{*}$. The mobility limited by acoustic phonon interacting through the piezoelectric potential is ${ }^{27}$

$$
\mu_{\mathrm{pe}}(\mathrm{n}, \mathrm{T})=\frac{2^{3 / 2} \pi \hbar^{2} \mathcal{E}_{0}}{\left(\mathrm{~m}^{*}\right)^{3 / 2} \mathrm{P}_{\mathrm{pe}}^{2} \mathrm{ekT}} \mathrm{E}_{\mathrm{f}}(\mathrm{n})^{1 / 2},
$$

where $\mathrm{P}_{\mathrm{pe}}$ is the piezoelectric constant. The phonon limited mobility is associated with these three phonon processes, i.e., $\mu_{\mathrm{ph}}{ }^{-1}=\mu_{\mathrm{po}}{ }^{-1}+\mu_{\mathrm{ac}}{ }^{-1}+\mu_{\mathrm{pe}}{ }^{-1}$.

The mobility limited by scatterings at the boundary, interface, and surface is given by ${ }^{25,28}$

$$
\mu_{\text {bdry }}(\mathrm{d}, \mathrm{n}, \mathrm{C})=\frac{\mathrm{e}}{\hbar} \frac{\mathrm{d} / \mathrm{C}}{\left(3 \pi^{2} \mathrm{n}\right)^{1 / 3}},
$$

where $\mathrm{d}$ is the film thickness and $\mathrm{C}$ is a constant dependent on the film/substrate system.

By combining the above equations, the donor and acceptor concentration can be solved as ${ }^{24}$

$$
\begin{aligned}
& \mathrm{N}_{\mathrm{D}}=\frac{\mathrm{n}}{\mathrm{Z}_{\mathrm{D}}\left(\mathrm{Z}_{\mathrm{D}}+\mathrm{Z}_{\mathrm{A}}\right)} \times\left\{\frac{\mu_{\mathrm{ii0}}(\mathrm{n})}{\mu_{\text {expt }}(\mathrm{T})}[1-\operatorname{Corr}(\mathrm{d}, \mathrm{n}, \mathrm{C}, \mathrm{T})]+\mathrm{Z}_{\mathrm{A}}\right\}, \\
& \mathrm{N}_{\mathrm{A}}=\frac{\mathrm{n}}{\mathrm{Z}_{\mathrm{A}}\left(\mathrm{Z}_{\mathrm{D}}+\mathrm{Z}_{\mathrm{A}}\right)} \times\left\{\frac{\mu_{\mathrm{ii} 0}(\mathrm{n})}{\mu_{\text {expt }}(\mathrm{T})}[1-\operatorname{Corr}(\mathrm{d}, \mathrm{n}, \mathrm{C}, \mathrm{T})]-\mathrm{Z}_{\mathrm{D}}\right\},
\end{aligned}
$$

where $\operatorname{Corr}(\mathrm{d}, \mathrm{n}, \mathrm{C}, \mathrm{T})=\frac{\mu_{\text {expt }}(\mathrm{T})}{\mu_{\mathrm{ph}}(\mathrm{n}, \mathrm{T})}+\frac{\mu_{\text {expt }}(\mathrm{T})}{\mu_{\text {bdry }}(\mathrm{d}, \mathrm{n}, \mathrm{C})}, \mathrm{Z}_{\mathrm{A}}$ and $\mathrm{Z}_{\mathrm{D}}$ is the charge state of the acceptor and donor, respectively, and $\mu_{\text {expt }}(\mathrm{T})$ is the experimental mobility.

To carry out the simulation, the following values were taken, namely, $T_{p o}=837 \mathrm{~K}, \varepsilon_{1}=3.72 \varepsilon_{v a c}$ and $\varepsilon_{0}=8.12 \varepsilon_{v a c}$, $c_{1}=1.4 \times 10^{11} \mathrm{Nm}^{-2}, E_{1}=3.8 \mathrm{eV}$, and $m^{*}=0.32 m_{0}$ (see references in Ref. 19). The film thickness was taken to be $d=300 \mathrm{~nm}$. $C$ was taken to be 2.5 , referring to the value obtained in $\mathrm{ZnO}$ grown by PLD on sapphire. ${ }^{28}$ The generated modeled curves of $\mu_{p h}, \mu_{b d r y}$, and $\mu_{i i}$ as well as the resultant mobility $\mu_{\text {total }}$ are shown in Fig. 8. The simulated resultant mobility curve well fitted the experimental data. It is also noticed from Fig. 8 that the dominant scattering process limiting the mobility was ionized impurity scattering throughout the whole measured temperature range from $10 \mathrm{~K}$ to $300 \mathrm{~K}$ $\left(\mu_{\mathrm{ii}}{ }^{-1} \cong \mu_{\mathrm{tot}}{ }^{-1}=\mu_{\mathrm{ii}}{ }^{-1}+\mu_{\mathrm{ph}}{ }^{-1}+\mu_{\mathrm{bdry}}{ }^{-1}\right.$ as $\mu_{\mathrm{ii}}{ }^{-1}$ is much larger than $\mu_{\mathrm{ph}}{ }^{-1}$ and $\mu_{\mathrm{bdry}}{ }^{-1}$ ).

The donor and acceptor concentrations of the sample can be calculated by Eqs. (7) and (8) with the input of their charges $\mathrm{Z}_{\mathrm{A}}$ and $\mathrm{Z}_{\mathrm{D}}$. Concerning the compensating acceptor, Tuomisto et al. ${ }^{29}$ showed by PAS that $\mathrm{V}_{\mathrm{Zn}}$ was the dominant compensating acceptor in n-type $\mathrm{ZnO}$. Moreover, Look et $a l .{ }^{24}$ reported the dramatic enhancement of $\mathrm{V}_{\mathrm{Zn}}$ in degenerately $\mathrm{n}^{+}$Ga-doped $\mathrm{ZnO}$ having a $n \sim 10^{21} \mathrm{~cm}^{-3}$ Ga-doped $\mathrm{ZnO}$ sample fabricated by PLD by the effect selfcompensation. For the present $\mathrm{n}^{+}$sample with the Fermi level very close to the conduction band minimum (CBM), $\mathrm{V}_{\mathrm{Zn}}$ would possess a charge of 2-, as it has the acceptor states of (0/-) and (-/2-) states in the band gap. For the Sb-doped $\mathrm{ZnO}$ sample, $\mathrm{Sb}_{\mathrm{Zn}}-2 \mathrm{~V}_{\mathrm{Zn}}{ }^{9}$ and $\mathrm{Sb}_{\mathrm{i}}-3 \mathrm{~V}_{\mathrm{Zn}}{ }^{23}$ are also acceptors that can compensate the electron concentration. $\mathrm{Sb}_{\mathrm{Zn}}-2 \mathrm{~V}_{\mathrm{Zn}}$ thus would possess a charge state of $3-$ as $S_{Z n}-2 V_{Z n}$ has two states of (0/-) and (-/3-) in the band gap, and $\mathrm{Sb}_{\mathrm{i}}-3 \mathrm{~V}_{\mathrm{Zn}}$ would possess a charge state of 1 - as it has a (0/-1) state in the band gap. The shallow donor responsible for the $\mathrm{n}^{+}$conductivity as found in the as-grown $\mathrm{Sb}$-doped $\mathrm{ZnO}$ in the present study had an ionization energy of $\sim 5 \mathrm{meV}$. Residual shallow donors in undoped $\mathrm{ZnO}$ usually had an ionization energy of $\sim 30 \mathrm{meV}$. It has been attributed to $\mathrm{H}^{5}$ (charge state of +1 ), and an intrinsic defect complex like $\mathrm{Zn}_{\mathrm{i}}-\mathrm{N}_{\mathrm{O}}{ }^{6}$ (having $(0 /+$ ) level in the band gap and thus a charge state of +1$)$, which had a charge state of +1 . The shallow donor as found in the as-grown $\mathrm{Sb}$-doped $\mathrm{ZnO}$ sample in the present study, which has an ionization energy of $\sim 5 \mathrm{meV}$, is unlikely the residual shallow donor commonly found in undoped $\mathrm{ZnO}$ materials. A theoretical study showed that $\mathrm{Sb}_{\mathrm{Zn}}$ was a deep donor ${ }^{14}$ having a state $(3+/+)$ in the band gap but the level was deep, but there exists also literature attributing the $\mathrm{n}^{+}$conductivity of Sb-doped $\mathrm{ZnO}$ to the $\mathrm{Sb}_{\mathrm{Zn}} \cdot{ }^{30}$ Though the charge states of the donor $\mathrm{Z}_{\mathrm{D}}$ and acceptor $\mathrm{Z}_{\mathrm{A}}$ are not exactly known, it is still worthy to estimate the values of $\mathrm{Z}_{\mathrm{A}}$ and $\mathrm{Z}_{\mathrm{D}}$ from Eqs. (7) and (8) by taking the values of $Z_{D}$ and $Z_{A}$ equal to 1,2 , and 3 , respectively, and the results are shown in Table I. Thus, from the table, $\mathrm{N}_{\mathrm{D}}$ and $\mathrm{N}_{\mathrm{A}}$ are in the ranges of $3.2 \times 10^{19}-2.7 \times 10^{20} \mathrm{~cm}^{-3}$ and $2.6 \times 10^{19}-2.5 \times 10^{20} \mathrm{~cm}^{-3}$, respectively. A very high acceptor concentration $\mathrm{N}_{\mathrm{A}}$ $\left(\sim 2 \times 10^{19}-2 \times 10^{20} \mathrm{~cm}^{-3}\right)$ was obtained in this as-grown $\mathrm{ZnO}: \mathrm{Sb}(2 \%)$ sample having $\mathrm{n}^{+} \sim 4 \times 10^{20} \mathrm{~cm}^{-3}$. A similarly high concentration of $\mathrm{V}_{\mathrm{Zn}}$ has been reported by Look et al. ${ }^{19}$ in Ga-doped $\mathrm{ZnO}\left(\mathrm{Ga}\right.$ concentration $\left.=1.4 \times 10^{21} \mathrm{~cm}^{-3}\right)$ grown by PLD on sapphire. This was attributed to the self-compensation, ${ }^{24}$ which was associated with the significant decrease of the formation energy $\mathrm{V}_{\mathrm{Zn}}$ as the Fermi level was degenerately close to the conduction band.

\section{Positron annihilation spectroscopic studies}

Because of its selective sensitivity towards Zn-vacancy related defects in $\mathrm{ZnO},{ }^{29,31}$ the PAS study was performed on the $\mathrm{Sb}$-doped $\mathrm{ZnO}$ samples $\left(\mathrm{Sb}=2 \%\right.$ and $\left.\mathrm{P}\left(\mathrm{O}_{2}\right)=1.3 \mathrm{~Pa}\right)$ 
TABLE I. The concentrations of donor $\mathrm{N}_{\mathrm{D}}$ and acceptor $\mathrm{N}_{\mathrm{A}}$ for the asgrown $\mathrm{ZnO}: \mathrm{Sb}(2 \%)$ sample estimated from the mobility data taking different possible charge states of the donor and acceptor $\left(\mathrm{Z}_{\mathrm{D}}\right.$ and $\left.\mathrm{Z}_{\mathrm{A}}\right)$.

\begin{tabular}{lll}
\hline \hline & $\mathrm{N}_{\mathrm{A}}\left(\mathrm{cm}^{-3}\right)$ & $\mathrm{N}_{\mathrm{D}}\left(\mathrm{cm}^{-3}\right)$ \\
\hline $\mathrm{Z}_{\mathrm{A}}=1 ; \mathrm{Z}_{\mathrm{D}}=1$ & $2.5 \times 10^{20}$ & $2.7 \times 10^{20}$ \\
$\mathrm{Z}_{\mathrm{A}}=1 ; \mathrm{Z}_{\mathrm{D}}=2$ & $1.6 \times 10^{20}$ & $9.0 \times 10^{19}$ \\
$\mathrm{Z}_{\mathrm{A}}=1 ; \mathrm{Z}_{\mathrm{D}}=3$ & $1.2 \times 10^{20}$ & $4.5 \times 10^{19}$ \\
$\mathrm{Z}_{\mathrm{A}}=2 ; \mathrm{Z}_{\mathrm{D}}=1$ & $8.4 \times 10^{19}$ & $1.9 \times 10^{20}$ \\
$\mathrm{Z}_{\mathrm{A}}=2 ; \mathrm{Z}_{\mathrm{D}}=2$ & $6.1 \times 10^{19}$ & $7.0 \times 10^{19}$ \\
$\mathrm{Z}_{\mathrm{A}}=2 ; \mathrm{Z}_{\mathrm{D}}=3$ & $4.7 \times 10^{19}$ & $3.8 \times 10^{19}$ \\
$\mathrm{Z}_{\mathrm{A}}=3 ; \mathrm{Z}_{\mathrm{D}}=1$ & $4.2 \times 10^{19}$ & $1.5 \times 10^{20}$ \\
$\mathrm{Z}_{\mathrm{A}}=3 ; \mathrm{Z}_{\mathrm{D}}=2$ & $3.3 \times 10^{19}$ & $5.8 \times 10^{19}$ \\
$\mathrm{Z}_{\mathrm{A}}=3 ; \mathrm{Z}_{\mathrm{D}}=3$ & $2.6 \times 10^{19}$ & $3.2 \times 10^{19}$ \\
\hline \hline
\end{tabular}

annealed at different annealing temperatures up to $900^{\circ} \mathrm{C}$ so as to investigate the thermal evolution of $\mathrm{Zn}$-vacancy related defects in the Sb-doped samples. The principal of PAS is that the outgoing positron-electron annihilation gamma photons carry the information of the electronic environment nearby the positron annihilation. ${ }^{31,32}$ Depth profiling of $\mathrm{Zn}$ vacancy related defects was obtained by scanning the positron incident energy and the mean positron implantation depth (in nm) was given by $\overline{\mathrm{x}}=(40 / \rho) \mathrm{E}^{1.6}, 31,32$ where $\rho$ is the material density in $\mathrm{g} / \mathrm{cm}^{3}$ and $E$ is the positron incident energy in $\mathrm{keV}$. The Doppler broadening of the annihilation peak in the gamma ray energy spectrum was parameterized by the S-parameter (as defined in the section Experimental). The measured S-parameter is the weighted contribution from the corresponding annihilation site, i.e., $S(E)=\sum_{i} f_{i}(E) S_{i}$, where $f_{i}(E)$ and $S_{i}$ are, respectively, the fraction of positrons annihilating at and the characteristic S-parameter of the i-th annihilation site The S-parameter as a function of the positron incident energy for the different samples (as-grown undoped and Sb-doped samples annealed at different temperatures) is shown in Fig. 9.

As shown in Fig. 9, the $S$ (E) plots of all the samples showed similar features. The S-parameter first decreased with increasing E (i.e., implantation depth) as the characteristic surficial S-parameter was larger than that of the sample $\mathrm{ZnO}$

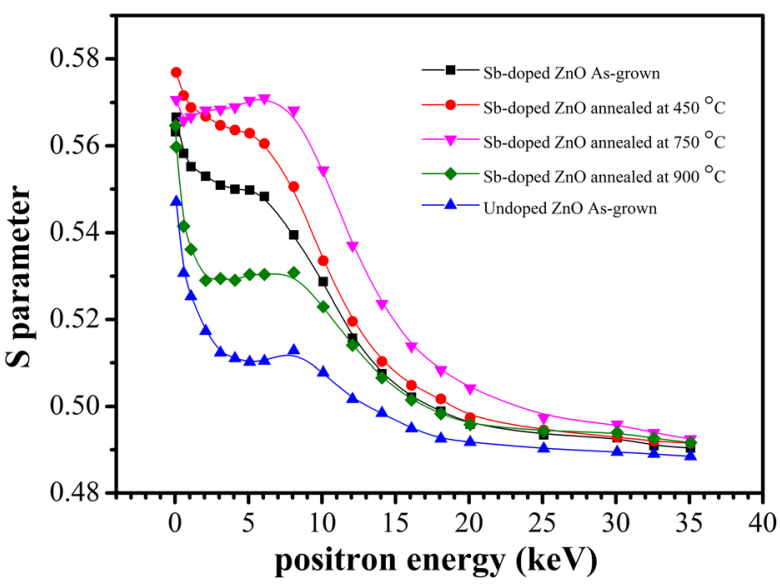

FIG. 9. The $S$ parameter as a function of incident positron energy for the as-grown undoped $\mathrm{ZnO}$ sample and the $\mathrm{ZnO}: \mathrm{Sb}(2 \%)$ samples annealed at different temperatures. All the samples were grown at the oxygen pressure of $1.3 \mathrm{~Pa}$. film. The S-parameter then reached a plateau at $2.5 \mathrm{keV}$ $<E<7 \mathrm{keV}$, which referred to the majority of incident positrons annihilated in the sample film. Further increasing E would inject positrons into the sapphire substrate and would lead to the decrease of the S-parameter as the characteristic $\mathrm{S}$-parameter of sapphire is lower than that of $\mathrm{ZnO}$. The S-parameter finally saturated at a large E as a majority of the incident positrons annihilated in the sapphire substrate. The S-parameters of the different $\mathrm{ZnO}$ film samples were thus taken at the positron incident energy of $5 \mathrm{keV}$. This corresponded to a mean depth of $\sim 100 \mathrm{~nm}$ which was at the mid of the $\mathrm{ZnO}$ film.

The S-parameter of the $\mathrm{Sb}$-doped $\mathrm{ZnO}(\mathrm{Sb}=2 \%$ and grown at $1.3 \mathrm{~Pa}$ ) samples against the annealing temperature was plotted in Fig. 10, and the electron concentration was also included here for comparison. The dramatic decrease of electron concentration after annealing at $750^{\circ} \mathrm{C}\left(4 \times 10^{20} \mathrm{~cm}^{-3}\right.$ for the as-grown sample to $5 \times 10^{16} \mathrm{~cm}^{-3}$ after annealing) is well correlated with the increase of the S-parameter.

Coincidence Doppler broadening (CDB) measurement is a PAS technique capable of offering electronic momentum distribution and thus the information of the chemical environment around the site that the positrons annihilate. ${ }^{31,32}$ In order to study the microstructure of the $\mathrm{Zn}$-vacancy related defects in the Sb-doped $\mathrm{ZnO}$ samples, $\mathrm{CDB}$ measurements were conducted. The electronic momentum distribution ratio curves of the $\mathrm{Sb}$ metal, the undoped $\mathrm{ZnO}$ film sample, the as-grown $\mathrm{ZnO}: \mathrm{Sb}(\mathrm{Sb}=1 \%-3 \%)$, and the $\mathrm{ZnO}: \mathrm{Sb}(2 \%)$ film samples annealed at different temperatures were normalized against the Bridgman grown $\mathrm{ZnO}$ single crystal, and the results are shown in Fig. 11. The $\mathrm{ZnO}$ single crystal is very close to the positron trap as compared to the PLD grown $\mathrm{ZnO}$ samples. The regions of the windows used for calculating the $\mathrm{S}$ and the $\mathrm{W}$-parameters are also included in the figure for reference. A peak centered at around $\mathrm{p}_{\mathrm{z}}=0$ was found in the ratio curve for the $\mathrm{Sb}$ sample, and was thus the fingerprint feature of the positron annihilating with the valence electrons of the $\mathrm{Sb}$ atom. Another feature of the $\mathrm{Sb}$-metal is that it has a very low distribution of electrons having a high momentum $\left(\mathrm{p}_{\mathrm{L}}>10 \times 10^{-3} \mathrm{~m}_{0} \mathrm{c}\right)$ as compared to the $\mathrm{ZnO}$ bulk (the reference sample taken as unity).

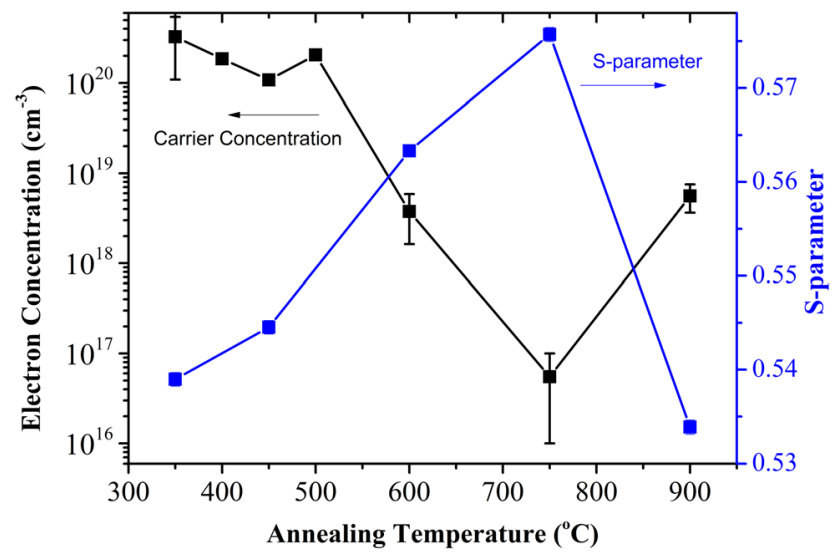

FIG. 10. Electron concentration and S-parameter as a function of the annealed temperature for the $\mathrm{ZnO}: \mathrm{Sb}(2 \%)$ samples grown at the oxygen pressure of $1.3 \mathrm{~Pa}$. 


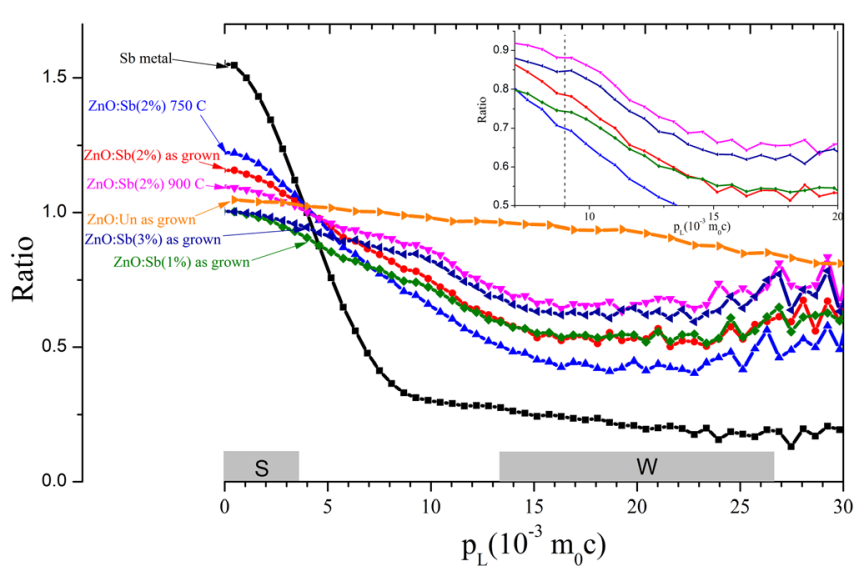

FIG. 11. The ratio curves of the electronic momentum distribution obtained from the $\mathrm{CDB}$ measurement for the undoped $\mathrm{ZnO}$ sample and the $\mathrm{ZnO}: \mathrm{Sb}$ samples with different $\mathrm{Sb}$ compositions and annealed at different temperatures. All the samples were grown with the oxygen pressure of $1.3 \mathrm{~Pa}$. The legends shown are ranked according to the intensity of the Sb-related peak at $\mathrm{p}=0$.

Similar features (i.e., peak at $\mathrm{p}_{\mathrm{L}}=0$ and low count at high $\mathrm{p}_{\mathrm{L}}$ ) were also observed in the ratio curves of all the annealed Sb-doped $\mathrm{ZnO}$ samples but not observed in those of the undoped $\mathrm{ZnO}$ sample. The Sb-related peak of the ratio curves for the Sb-doped $\mathrm{ZnO}$ samples was associated with positrons annihilating in the Zn-vacancy complex decorated with the $\mathrm{Sb}$, while the peak intensities reflected the concentration of this defect complex. The increase of the Sparameter after annealing at $750{ }^{\circ} \mathrm{C}$ (Fig. 10) can thus be understood as the increase of the count in the S-parameter window of the CDB spectra, which is characteristic of the positron annihilating with the $\mathrm{Sb}$ atom.

As shown in the ratio curves in Fig. 11, the intensity of the $\mathrm{Sb}$ related peak for the $\mathrm{ZnO}: \mathrm{Sb}(2 \%)$ sample was enhanced after annealing at $750{ }^{\circ} \mathrm{C}$, and then decreased after annealing at the higher temperature of $900{ }^{\circ} \mathrm{C}$. It is noticed that the electron concentration anti-correlates with the Sb-related peak intensity in the CDB spectra. It is thus suggested that these electron concentration drops induced by $750{ }^{\circ} \mathrm{C}$ annealing are related to the $\mathrm{V}_{\mathrm{Zn}}-\mathrm{Sb}$ defect complex detected by CDB spectroscopy, which acts as the compensating defect. It was also worthy to point out that some $\mathrm{V}_{\mathrm{Zn}}-\mathrm{Sb}$ defect complex already existed in the as-grown sample. With first principles calculation, Limpijumnong et al. ${ }^{14}$ suggested that $\mathrm{Sb}_{\mathrm{Zn}}-2 \mathrm{~V}_{\mathrm{Zn}}$ was a shallow acceptor having a low formation energy. Puchaia and Morgan ${ }^{23}$ reported that $\mathrm{Sb}_{\mathrm{i}}-3 \mathrm{~V}_{\mathrm{Zn}}$ was the stable deep acceptor in $\mathrm{ZnO}$. These two acceptor defect complexes could be the candidate of the $\mathrm{V}_{\mathrm{Zn}}-\mathrm{Sb}$ complex, though only the present $\mathrm{CDB}$ data cannot offer information for distinguishing its exact microstructure between these two defect complexes.

\section{XPS study}

XPS study was performed to study the chemical states of $\mathrm{Sb}$ in the $\mathrm{ZnO}: \mathrm{Sb}$ samples. Figures 12(a)-12(c), respectively, show the XPS spectra of the $\mathrm{Sb} 3 \mathrm{~d}_{3 / 2}$ state of the as-grown $\mathrm{ZnO}: \mathrm{Sb}(2 \%)$ sample and those upon annealing at 750 and $900{ }^{\circ} \mathrm{C}$. The $3 \mathrm{~d}_{3 / 2}$ peaks were fitted by the $\mathrm{Sb}^{3+}$ and $\mathrm{Sb}^{5+}$ peaks locating at $\sim 540.2 \mathrm{eV}$ and $540.8 \mathrm{eV}$, respectively. ${ }^{33}$ The fitted intensity ratios of the peaks $\mathrm{Sb}^{5+} / \mathrm{Sb}^{3+}$ are $1.61,4.82$, and 2.33 for the as-grown, 750 , and $900{ }^{\circ} \mathrm{C}$ annealed $\mathrm{ZnO}: \mathrm{Sb}$ samples, respectively. The maximum $\mathrm{Sb}^{5+} / \mathrm{Sb}^{3+}$ intensity ratio at the annealing temperature of $750{ }^{\circ} \mathrm{C}$ well anti-correlates with the minimum of the electron concentration (see Fig. 6), for which the discussion will be given in the upcoming Discussion section. The $\mathrm{Zn} 2 \mathrm{p}_{3 / 2}$ XPS spectrum located at $1021.9 \mathrm{eV}$ of the $\mathrm{ZnO}: \mathrm{Sb}(2 \%)$ with different annealing conditions is shown in Fig. 12(d), for which no significant difference is found among these spectra.

\section{E. PL study}

Figure 13 shows the near band edge emission (NBE) of the low temperature $(10 \mathrm{~K})$ PL spectra for the as-grown $\mathrm{ZnO}: \mathrm{Sb}(2 \%)$ samples and that annealed at $750{ }^{\circ} \mathrm{C}$. The peak at $3.36 \mathrm{eV}$ is found in both samples, and a similar peak has

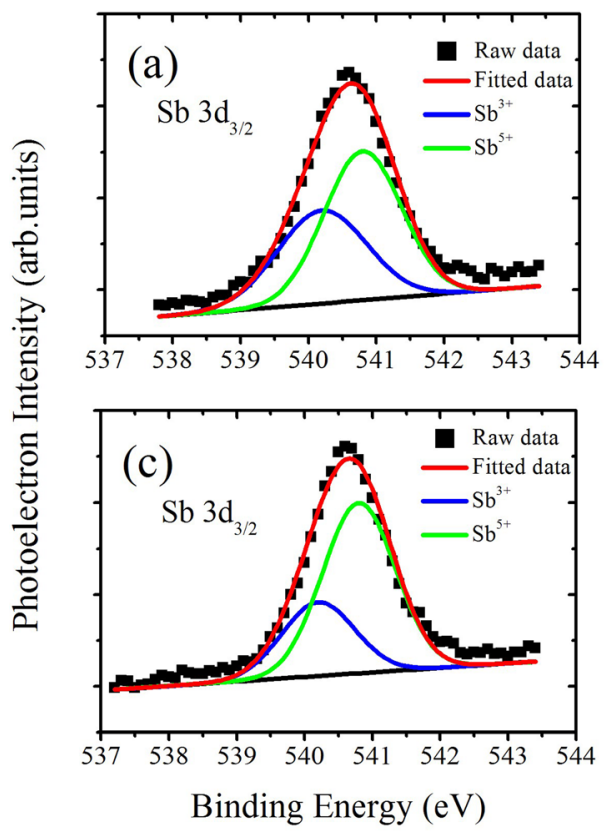

Binding Energy (eV)
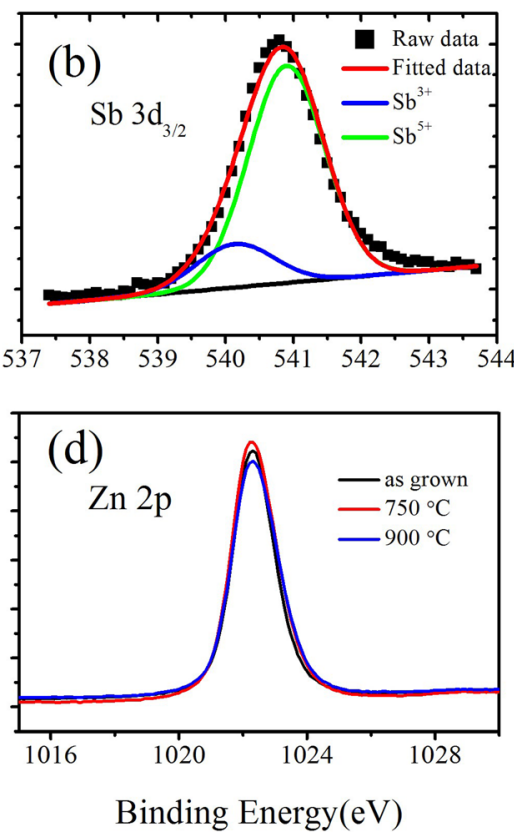

FIG. 12. The XPS spectra of the $\mathrm{ZnO}: \mathrm{Sb}(2 \%)$ films: the $\mathrm{Sb} 3 \mathrm{~d}_{3 / 2}$ state for (a) the as-grown, (b) those annealed at $750^{\circ} \mathrm{C}$, and (c) annealed at $900^{\circ} \mathrm{C}$; (d) the $\mathrm{Zn} 2 \mathrm{p}_{3 / 2}$ state. The samples were grown with $\mathrm{P}\left(\mathrm{O}_{2}\right)=1.3 \mathrm{~Pa}$. The $\mathrm{Sb} 3 \mathrm{~d}_{3 / 2}$ peaks were fitted by two Gaussian peaks, namely, associated with the $\mathrm{Sb}^{3+}$ and $\mathrm{Sb}^{5+}$ states. 


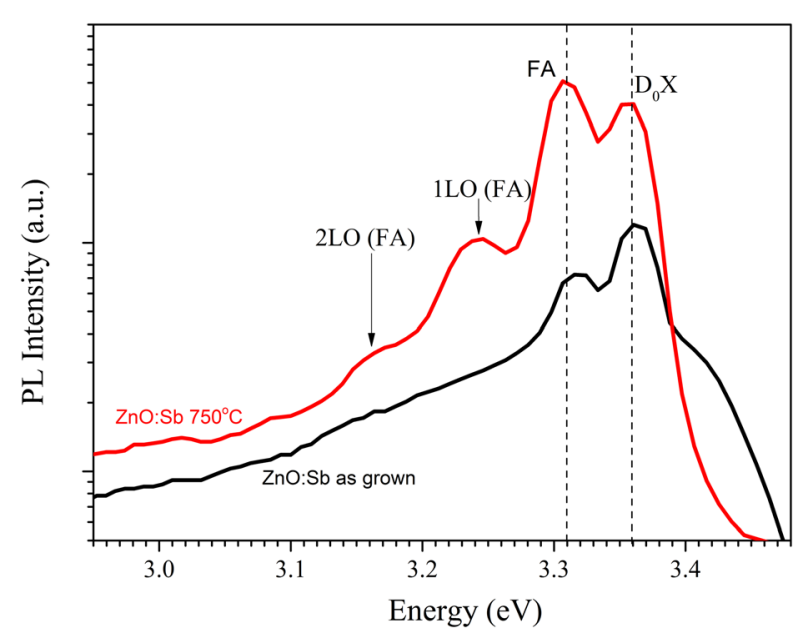

FIG. 13. The PL spectra for the as-grown $\mathrm{ZnO}: \mathrm{Sb}(2 \%)$ and those annealed at $750^{\circ} \mathrm{C}$. These sample were grown under $\mathrm{P}\left(\mathrm{O}_{2}\right)=1.3 \mathrm{~Pa}$.

been assigned to the neutral donor bound exciton $\left(\mathrm{D}^{0} \mathrm{X}\right)$ emission (Refs. 1 and 35 and references therein). The shoulder at $\sim 3.42 \mathrm{eV}$ was only observed in the as-grown $\mathrm{ZnO}: \mathrm{Sb}$ sample, which has been reported to be associated with the A free exciton first excited-state transition $\mathrm{FX}_{\mathrm{A}}{ }^{\mathrm{n}=2} \cdot{ }^{36}$ For the as-grown $\mathrm{ZnO}: \mathrm{Sb}$ sample, a PL emission at $3.32 \mathrm{eV}$ is found and its intensity is lower than the $\mathrm{D}^{0} \mathrm{X}$ emission. After annealing at $750{ }^{\circ} \mathrm{C}$, this emission slightly red-shifts to $3.31 \mathrm{eV}$ and its intensity is higher than that of the $\mathrm{D}^{0} \mathrm{X}$ line. Emission at around $3.32 \mathrm{eV}$ has been associated to the twoelectron satellite (TES) transition of the neutral donor bound exciton (Refs. 1 and 35 and references therein). However, the $3.31 \mathrm{eV}$ emission as seen in the annealed $\mathrm{ZnO}: \mathrm{Sb}$ sample is not likely due to the TES as the TES emission has an intensity lower than the $\mathrm{D}_{0} \mathrm{X}$ emission. The $3.32 \mathrm{eV}$ emission as seen in the annealed $\mathrm{ZnO}: \mathrm{Sb}$ sample is suggested to have originated from the free-to-acceptor (FA) transition. Emissions of $3.25 \mathrm{eV}$ and $3.17 \mathrm{eV}$ are also observed in the annealed $\mathrm{ZnO}: \mathrm{Sb}$ sample, and these lines are attributed to the first and second phonon replica (1LO and 2LO, respectively) of the FA emission as they are separated by $\sim 70 \mathrm{meV}$. The acceptor binding energy was calculated by $\mathrm{E}_{\mathrm{A}}=\mathrm{E}_{\mathrm{g}}-\mathrm{E}_{\mathrm{FA}}+\mathrm{kT} / 2$, where $\mathrm{E}_{\mathrm{g}}=3.44 \mathrm{eV}$ and $\mathrm{E}_{\mathrm{FA}}$ $=3.32 \mathrm{eV}$, and a value of $\mathrm{E}_{\mathrm{A}}=0.12 \mathrm{eV}$ was yielded. For the as-grown $\mathrm{ZnO}: \mathrm{Sb}$ sample, it is difficult to distinguish whether the $3.31 \mathrm{eV}$ emission (which is slightly bluer than the FA found in the as-grown $\mathrm{ZnO}: \mathrm{Sb}$ sample) is associated with the TES or the FA. Nevertheless, it is plausible to conclude that annealing the $\mathrm{ZnO}: \mathrm{Sb}$ sample at $750{ }^{\circ} \mathrm{C}$ enhances the FA emission associated with the shallow acceptor with a binding energy of $120 \mathrm{meV}$.

\section{DISCUSSION}

The undoped $\mathrm{ZnO}$ sample has $\mathrm{n} \sim 1 \times 10^{18} \mathrm{~cm}^{-3}$, and all the as-grown $\mathrm{Sb}$-doped $\mathrm{ZnO}$ samples with $\mathrm{Sb}=0.5 \%$ to $2 \%$ are $\mathrm{n}^{+}$conductive having an electron concentration larger than $\sim 10^{20} \mathrm{~cm}^{-3}$. For the high $\mathrm{Sb}$ composition of $3 \%$, the carrier drops abruptly and the sample becomes highly resistive. For the low $\mathrm{Sb}$ composition $\leq 2 \%$, the electron concentration of the as-grown $\mathrm{ZnO}: \mathrm{Sb}$ samples increases with the
$\mathrm{Sb}$ doping composition and is effectively equal to the $\mathrm{Sb}$ concentration. In addition, the ionization energy of the shallow donor is $\sim 5 \mathrm{meV}$, which is not close to that found in the undoped $\mathrm{ZnO}$ materials. ${ }^{5,6}$ It is thus plausible to associate the $\mathrm{n}^{+}$conductivity to the $\mathrm{Sb}$ related shallow donor. Substitutional defects of $\mathrm{Sb}$ into $\mathrm{Zn}$-site $\mathrm{Sb}_{\mathrm{Zn}}$ and O-site $\mathrm{Sb}_{\mathrm{O}}$ are, respectively, the donor and acceptor. The first principle calculations showed that the $\mathrm{Sb}_{\mathrm{Zn}}$ was a deep donor. ${ }^{14}$ However, similar to the findings in the present study, Liu et al. ${ }^{30}$ and Heo et al. ${ }^{34}$ observed $\mathrm{n}^{+}$type conductivity in Sbdoped and $\mathrm{P}$-doped $\mathrm{ZnO}$ with a relatively low doping composition, and the materials became highly resistive as the dopant compositions were high. The shallow donors responsible for the $\mathrm{n}^{+}$conductivity were attributed to the $\mathrm{Sb}$ and $\mathrm{P}$ substitutional defect of the Zn-site or the relevant defect complex. In the present study, the temperature dependent measurement revealed that the shallow donor had an ionization energy of $\sim 5 \mathrm{meV}$, and was unlikely associated with the shallow donors like hydrogen or the intrinsic defect complex which had an ionization energy of $\sim 35 \mathrm{meV}{ }^{6,35}$ The ionic radius of $\mathrm{Sb}^{3-}$ of $2.44 \AA$ is much larger than that of $\mathrm{O}^{2-}$ $\left(1.38 \AA\right.$ ) (see references in Ref. 34). The ionic radii of $\mathrm{Zn}^{2+}$ and $\mathrm{Sb}^{3+}$ are close to each other and having values of $0.74 \AA$ and $0.62 \AA$, respectively (see references in Ref. 34). The $\mathrm{Sb}$ dopant is thus more likely to occupy the $\mathrm{Zn}$-site of the $\mathrm{ZnO}$ lattice, whereas $\mathrm{Sb}_{\mathrm{Zn}}$ is a donor type defect. Using the conversion-electron emission channeling from radioactive $\mathrm{Sb}$ and As, Wahl et al. ${ }^{15}$ studied the $\mathrm{Sb}$ and As-implanted $\mathrm{ZnO}$ single crystal with the Sb concentration $\approx 2 \times 10^{19} \mathrm{~cm}^{-3}$ (estimated from the dose and implantation given), which was lower than that of all the present Sb-doped $\mathrm{ZnO}$ samples. It was found that the majority of the $\mathrm{Sb}$ and As occupied the $\mathrm{Zn}$ site of the $\mathrm{ZnO}$ lattice. It is plausible to attribute the shallow donor responsible for the $\mathrm{n}^{+}$conductivity in the $\mathrm{ZnO}: \mathrm{Sb}$ samples with $\mathrm{Sb} \leq 2 \%$ of the present study to the $\mathrm{Sb}_{\mathrm{Zn}}$ or its complex defect.

An annealing study of the $\mathrm{ZnO}: \mathrm{Sb}$ sample with $\mathrm{Sb}=2 \%$ shows that annealing at $750{ }^{\circ} \mathrm{C}$, significantly reduces the material electron concentration by larger than the factor of 1000 . The electron concentrations for the undoped $\mathrm{ZnO}$ grown by the same PLD system, similar growth parameters, and annealing temperatures are in the range of $10^{18}-10^{19} \mathrm{~cm}^{-3}$. As the electron concentration of the $\mathrm{ZnO}: \mathrm{Sb}(2 \%)$ grown with $\mathrm{P}\left(\mathrm{O}_{2}\right)=5 \mathrm{~Pa}$ dropped from $10^{20} \mathrm{~cm}^{-3}$ to $10^{14} \mathrm{~cm}^{-3}$ after annealing at $750^{\circ} \mathrm{C}$, the electron concentration drop cannot be solely due to the removal of the $\mathrm{Sb}_{\mathrm{Zn}}$ but must be originated to the formation of compensating defects with concentration $\sim 10^{20} \mathrm{~cm}^{-3}$. The concentration of $\mathrm{V}_{\mathrm{Zn}}\left(10^{19}-10^{20} \mathrm{~cm}^{-3}\right)$ was enhanced in the as-grown degenerate $\mathrm{ZnO}: \mathrm{Sb}$ (say 2\%) with $\mathrm{n}^{+} \sim 10^{20} \mathrm{~cm}^{-3}$ due to the self-compensation effect while the Fermi level was close to the conduction band and thus the formation energy of $\mathrm{V}_{\mathrm{Zn}}$ was low. However, the $\mathrm{V}_{\mathrm{Zn}}$ concentration in the $\mathrm{ZnO}: \mathrm{Sb}$ sample annealed at $750^{\circ} \mathrm{C}$ cannot be as high as $\sim 10^{20} \mathrm{~cm}^{3}$ because the $\mathrm{E}_{\mathrm{F}}$ is not close to the $\mathrm{E}_{\mathrm{C}}$ and the formation energy of $\mathrm{V}_{\mathrm{Zn}}$ is not lowered by the selfcompensation effect. Thus, the compensating defect formed upon annealing at $750^{\circ} \mathrm{C}$ cannot be $\mathrm{V}_{\mathrm{Zn}}$.

The annealing inducing a drop of electron concentration well correlates with the increase of the $\mathrm{V}_{\mathrm{Zn}}-\mathrm{Sb}$ defect 
concentration as detected by the CDBS. Theoretical studies using local density approximation (LDA) and generalized gradient approximation $(\mathrm{GGA})^{14,23}$ reported that the $\mathrm{Sb}_{\mathrm{Zn}}$ substitutional defect was a deep donor, and the $\mathrm{Sb}_{\mathrm{Zn}}-2 \mathrm{~V}_{\mathrm{Zn}}$ defect complex was a shallow acceptor having a low formation energy and an ionization energy of $\varepsilon(0 /-)=0.16 \mathrm{eV}$. With $a b$ initio calculations, Puchala and Morgan ${ }^{23}$ showed that the $\mathrm{Sb}_{\mathrm{i}}-3 \mathrm{~V}_{\mathrm{Zn}}$ defect complex was energetically stable and was a deep acceptor at $\varepsilon(0 /-)=0.28 \mathrm{eV}$. The drop of the electron concentration induced by the $750{ }^{\circ} \mathrm{C}$ annealing is thus attributed to the formation of annealing induced formation of the $\mathrm{V}_{\mathrm{Zn}}-\mathrm{Sb}$ defect complex like the $\mathrm{Sb}_{\mathrm{Zn}}-2 \mathrm{~V}_{\mathrm{Zn}}$ or the $S b_{i}-3 V_{Z n}$ acceptors which compensate the free carrier. Further increasing the annealing temperature led to an increase of the electron concentration of the $\mathrm{ZnO}: \mathrm{Sb}$ sample. This could be due to thermal dissociation of the $\mathrm{V}_{\mathrm{Zn}}-\mathrm{Sb}$ acceptor complex, which is evidenced by the drop of the Sbrelated peak intensity in the CDB spectra after the annealing at $900{ }^{\circ} \mathrm{C}$.

In previous systematic studies of $\mathrm{ZnO}$ :As grown on the $\mathrm{Si}$ substrate using the radio frequency sputtering technique, ${ }^{18,19}$ the XPS study showed that a majority of the As dopant occupied the $\mathrm{Zn}$ site of the $\mathrm{ZnO}$ lattice. The as-grown $\mathrm{ZnO}$ :As sample was n-type and annealing at $600^{\circ} \mathrm{C}$ converted the conductivity to $\mathrm{p}$-type with a hole concentration of $6 \times 10^{17} \mathrm{~cm}^{-3}$. The annealing induced p-type conductivity was associated with the formation of the $\mathrm{As}_{\mathrm{Zn}}-2 \mathrm{~V}_{\mathrm{Zn}}$ shallow acceptor complex. Increasing the annealing temperature to $800^{\circ} \mathrm{C}$ changed the conductivity to $\mathrm{n}$-type and this was associated with the dissociation of the $\mathrm{As}_{\mathrm{Zn}}-2 \mathrm{~V}_{\mathrm{Zn}}$ shallow acceptor complex. The annealing temperature for the dissociation of the $\mathrm{As}_{\mathrm{Zn}}-2 \mathrm{~V}_{\mathrm{Zn}}$ defect was estimated by its theoretical binding energy ${ }^{19}$ and the value was found to be $800^{\circ} \mathrm{C}$, which was close to the present observed temperature of $900^{\circ} \mathrm{C}$.

It is noticed from Fig. 3(a) that the lattice constant of the $\mathrm{ZnO}(002)$ peak dropped slightly after annealing at $750^{\circ} \mathrm{C}$, which is the annealing temperature for enhancing the $\mathrm{V}_{\mathrm{Zn}}-\mathrm{Sb}$ acceptor complex formation $\left(\mathrm{Sb}_{\mathrm{Zn}}-2 \mathrm{~V}_{\mathrm{Zn}}\right.$ or $\left.\mathrm{Sb}_{\mathrm{i}}-3 \mathrm{~V}_{\mathrm{Zn}}\right)$ and suppressing the electron concentration. If the $\mathrm{V}_{\mathrm{Zn}}-\mathrm{Sb}$ acceptor complex formed is the $S b_{i}-3 V_{Z n}$ defect, it is expected that the formation of the $\mathrm{Sb}$ interstitial would introduce an increase of the lattice constant of the $\mathrm{ZnO}$ (002) peak, but the opposite trend is observed. It is more likely that the involved thermally created acceptor complex is the $\mathrm{Sb}_{\mathrm{Zn}}-2 \mathrm{~V}_{\mathrm{Zn}}$ shallow acceptor.

The XPS study on the chemical state of $\mathrm{Sb}$ in the $\mathrm{ZnO}: \mathrm{Sb}$ (2\%) samples upon different annealing temperatures showed that the $\mathrm{Sb}^{5+} / \mathrm{Sb}^{3+}$ ratio in the samples anti-correlates with the electron concentration and correlates with the $\mathrm{V}_{\mathrm{Zn}}$-Sb acceptor complex concentration. Pandey et al. ${ }^{33}$ carried out the XPS study on $\mathrm{Sb}$-doped $\mathrm{ZnO}$ fabricated by dual ion beam sputtering and a high $\mathrm{Sb}^{5+} / \mathrm{Sb}^{3+}$ ratio was correlated with the hole concentration, and thus the $\mathrm{Sb}_{\mathrm{Zn}}-2 \mathrm{~V}_{\mathrm{Zn}}$ shallow acceptor. This result is consistent with the assignment of the $\mathrm{V}_{\mathrm{Zn}}-\mathrm{Sb}$ acceptor complex to $S b_{Z n}-2 V_{Z n}$, rather than $S b_{i}-3 V_{Z n}$ as $S b_{i}-3 V_{Z n}$ is a deep acceptor.

Annealing the $\mathrm{ZnO}: \mathrm{Sb}(2 \%)$ sample at $750^{\circ} \mathrm{C}$ enhances the FA peak (at $3.31 \mathrm{eV}$ ) in the PL spectrum, and the corresponding acceptor has the binding energy of $\sim 120 \mathrm{meV}$, which compensated the $\mathrm{n}^{+}$conductivity and revealed the CDB spectra. As the acceptor is shallow rather than deep, it should be $S b_{Z n}-2 V_{Z n}$ rather than $S b_{i}-3 V_{Z n}$. The binding energy of this acceptor is $120 \mathrm{meV}$, though not exactly matching but close to the value of $\varepsilon(0 /-)=160 \mathrm{meV}$ of $\mathrm{Sb}_{\mathrm{Zn}^{-}}$ $2 \mathrm{~V}_{\mathrm{Zn}}$ as obtained from first principles calculation. ${ }^{14}$

Despite the $\mathrm{Sb}_{\mathrm{Zn}}-2 \mathrm{~V}_{\mathrm{Zn}}$ acceptor being formed after annealing at $750{ }^{\circ} \mathrm{C}$, the resulting samples were n-type rather than p-type. This could be due to the compensation of holes by the donors and/or deep traps (intrinsic or impurity defect) remaining in the annealed samples. SIMS measurement was conducted on the $\mathrm{ZnO}: \mathrm{Sb}(2 \%)$ grown at $\mathrm{P}\left(\mathrm{O}_{2}\right)=1.3 \mathrm{~Pa}$ with annealing at $750{ }^{\circ} \mathrm{C}$, and the $\mathrm{H}$ concentration remained at quite a high level of $3 \times 10^{19} \mathrm{~cm}^{-3}$.

While fixing the $\mathrm{Sb}$ composition at $1 \%$, the electron concentration grown with $\mathrm{P}\left(\mathrm{O}_{2}\right)=0$ is $5 \times 10^{20} \mathrm{~cm}^{-3}$ and it drops with increasing oxygen pressure during growth (see Fig. 5). The electron concentration then saturated at $\mathrm{P}$ $\left(\mathrm{O}_{2}\right)=1.3 \mathrm{~Pa}$ with $\mathrm{n} \sim 9 \times 10^{19} \mathrm{~cm}^{-3}$. This could be due to the increase of the concentrations of $\mathrm{V}_{\mathrm{Zn}}$ and/or its related acceptor like $\mathrm{Sb}_{\mathrm{Zn}}-2 \mathrm{~V}_{\mathrm{Zn}}$ as a result from increasing the oxygen growth pressure, which then compensated the free electrons.

The electron concentration increases with the Sb concentration for $\mathrm{Sb}$ composition $\leq 2 \%$, but it dropped abruptly as the $\mathrm{Sb}$ composition increases to $3 \%$ (which referred to the $\mathrm{Sb}$ concentration of $8 \times 10^{20} \mathrm{~cm}^{-3}$, as seen in Fig. 4). The increase of electron concentration with the $\mathrm{Sb}$ concentration can be easily understood as the increase of the $\mathrm{Sb}_{\mathrm{Zn}}$ related shallow donor, but this cannot explain the abrupt change of the sample to highly resistive as the Sb composition further increases to $3 \%$. This could be due to the formation of a compensation defect which was associated with the distortion of the lattice structure like $\mathrm{Sb}_{\mathrm{O}}$ (which had a large mismatch in the lattice constant) or interstitial.

Liu et al. ${ }^{30}$ studied the $\mathrm{Sb}$ dopant defect in Sb-doped $\mathrm{ZnO}$ grown by plasma enhanced MBE. The conductivity changed from $\sim 10^{20} \mathrm{~cm}^{-3}$ to $\sim 10^{17} \mathrm{~cm}^{-3}$ as the $\mathrm{Sb}$ cell temperature was raised to $\sim 475^{\circ} \mathrm{C}$ (which approximately corresponded to the $\mathrm{Sb}$ composition of 1 at. \%, i.e., $4.4 \times 10^{20} \mathrm{~cm}^{-3}$ ). The lattice constant and the FWHM of the $\mathrm{ZnO}(002)$ peak of the XRD spectra remained constant as the $\mathrm{Sb}$ cell temperature was in the range of $370^{\circ} \mathrm{C}$ to $475^{\circ} \mathrm{C}$. It was because the ionic radius of $\mathrm{Sb}^{3+}$ was close to that of $\mathrm{Zn}^{2+}$ and thus the incorporation of $\mathrm{Sb}$ into the $\mathrm{Zn}$ site to form the shallow donor would not deteriorate the lattice structure. However, the lattice constant and the FWHM of the (002) peak increase significantly as the Sb cell temperature increased to $475^{\circ} \mathrm{C}$. It was explained by the occupation of the $\mathrm{Sb}$ atom into the $\mathrm{O}$ site rather than the $\mathrm{Zn}$ site for a high $\mathrm{Sb}$ concentration $\geq 4.4 \times 10^{20} \mathrm{~cm}^{-3}$, as there was a large mismatch between the ionic radii of $\mathrm{Sb}^{3-}(2.44 \AA)$ and $\mathrm{O}^{2-}$ $\left(1.38 \AA\right.$ ). The $\mathrm{Sb}_{\mathrm{O}}$ (which was the deep acceptor) or its related complex thus compensates the electron concentration for the $\mathrm{Sb}$-doped $\mathrm{ZnO}$ samples with a high Sb concentration. Similar correlated carrier compensation, and increases in the lattice constant and FWHM of the $\mathrm{ZnO}$ (002) peak are observed in the present study with a limiting Sb concentration of $8 \times 10^{20} \mathrm{~cm}^{-3}$, which is also close to that found by 
Liu et al. ${ }^{30}$ It is thus plausible to associate the carrier compensation observed at the limiting $\mathrm{Sb}$ composition of $3 \%$ (i.e., $\mathrm{Sb}$ concentration $\sim 8 \times 10^{20} \mathrm{~cm}^{-3}$ ) to the formation of the $\mathrm{Sb}_{\mathrm{O}}$ acceptor or its related defect complex. However, the physics behind the change of the $\mathrm{Sb}$ occupation from the $\mathrm{Zn}$ site to the $\mathrm{O}$ site as the $\mathrm{Sb}$ concentration is high is not yet understood and requires further investigation.

The variation of the $\mathrm{Sb}_{\mathrm{Zn}}-2 \mathrm{~V}_{\mathrm{Zn}}$ peak intensity in the CDB spectra (Fig. 11) with the change of the Sb composition in the as-grown $\mathrm{ZnO}: \mathrm{Sb}$ samples can also be understood with the formation of $\mathrm{Sb}_{\mathrm{O}}$ with a large $\mathrm{Sb}$ composition. As shown in Fig. 11, the $\mathrm{Sb}_{\mathrm{Zn}}-2 \mathrm{~V}_{\mathrm{Zn}}$ related peak intensity increases as the $\mathrm{Sb}$ composition increases from $1 \%$ to $2 \%$. It is because for the case of $\mathrm{Sb} \leq 3 \%, \mathrm{Sb}$ occupies the $\mathrm{Zn}$ site and thus increasing the $\mathrm{Sb}$ composition increases the chance of forming the $\mathrm{Sb}_{\mathrm{Zn}}-2 \mathrm{~V}_{\mathrm{Zn}}$ defect complex. As the $\mathrm{Sb}$ composition further increases to $3 \%$, the $\mathrm{Sb}_{\mathrm{Zn}}-2 \mathrm{~V}_{\mathrm{Zn}}$ related peak intensity decreases because $\mathrm{Sb}$ starts occupying the $\mathrm{O}$ site for a high $\mathrm{Sb}$ composition and thus suppressing the formation of the $\mathrm{Sb}_{\mathrm{Zn}}-2 \mathrm{~V}_{\mathrm{Zn}}$ defect complex.

Another interesting feature is also noticed in the $\mathrm{CDB}$ spectra of the Sb-doped $\mathrm{ZnO}$ samples. A shoulder is observed at $\mathrm{p}_{\mathrm{L}} \sim 9 \times 10^{-3} \mathrm{~m}_{0} \mathrm{c}(\sim 1.2$ a.u. $)$ in the CDB spectra all of the Sb-doped $\mathrm{ZnO}$ samples, but except the $\mathrm{ZnO}: \mathrm{Sb}$ (2\%) sample annealed at $750{ }^{\circ} \mathrm{C}$ in which the shoulder is barely observable. The corresponding magnified spectra are shown in the inset of Fig. 11. Makkonen et al. ${ }^{37}$ calculated the ratio curves of different $\mathrm{V}_{\mathrm{Zn}}$-related defects in $\mathrm{ZnO}$. A similar shoulder was found in the calculated ratio curves of $\mathrm{V}_{\mathrm{Zn}}$ and $\mathrm{V}_{\mathrm{Zn}} \mathrm{V}_{\mathrm{O}}$, for which the two calculated ratio curves were very close and thus experimental distinguishing is not feasible. This shoulder was originated from the positron trapped at $\mathrm{V}_{\mathrm{Zn}}$ and annihilating with the $\mathrm{Zn}$ cation electron. The absence of the shoulder in the $\mathrm{ZnO}: \mathrm{Sb}(2 \%)$ sample annealed at $750{ }^{\circ} \mathrm{C}$ can be explained by the fact that there is negligibly isolated $\mathrm{V}_{\mathrm{Zn}}$ and a majority of $\mathrm{V}_{\mathrm{Zn}}$ is bound with $\mathrm{Sb}_{\mathrm{Zn}}$ to form the $\mathrm{Sb}_{\mathrm{Zn}}-2 \mathrm{~V}_{\mathrm{Zn}}$, and thus positrons trapped in the $\mathrm{V}_{\mathrm{Zn}}$ open volume annihilate with the $\mathrm{Sb}$ atom rather than the $\mathrm{Zn}$ atom. The $\mathrm{ZnO}: \mathrm{Sb}(2 \%)$ sample annealed at $900^{\circ} \mathrm{C}$ has a strong $\mathrm{V}_{\mathrm{Zn}}$ related shoulder in the ratio curve (see the inset of Fig. 11). This observation supports the argument made in the previous paragraph that the $\mathrm{Sb}_{\mathrm{Zn}}-2 \mathrm{~V}_{\mathrm{Zn}}$ dissociates into $\mathrm{Sb}_{\mathrm{Zn}}$ and $\mathrm{V}_{\mathrm{Zn}}$ after annealing at $900^{\circ} \mathrm{C}$. The asgrown $\mathrm{ZnO}: \mathrm{Sb}(3 \%)$ sample also has the strong $\mathrm{V}_{\mathrm{Zn}}$ related shoulder. For the as-grown $\mathrm{Sb}$ doped $\mathrm{ZnO}$ samples with relatively low $\mathrm{Sb}$ compositions of $1 \%$ and $2 \%$, the $\mathrm{Sb}_{\mathrm{Zn}}-2 \mathrm{~V}_{\mathrm{Zn}}$ defect complex already exists in the as-grown samples with some co-existence of isolated $\mathrm{V}_{\mathrm{Zn}}$. For the high $\mathrm{Sb}$ composition sample with $\mathrm{Sb}=3 \%$, the $\mathrm{Sb}$ starts occupying the $\mathrm{O}$ site as $\mathrm{Sb}_{\mathrm{O}}$. Thus, the formation of $\mathrm{Sb}_{\mathrm{Zn}}-2 \mathrm{~V}_{\mathrm{Zn}}$ is suppressed and there is more isolated $\mathrm{V}_{\mathrm{Zn}}$.

According to the S-parameter window as indicated and the peak intensity of ratio curves at $p_{L}=0$ in Fig. 11, it can be observed that the ratio at the peak is well correlated with the measured S-parameter. The ratio of pure $\mathrm{Sb}$ at $\mathrm{p}_{\mathrm{L}}=0$ is 1.55 as shown in Fig. 11, and that for the $\mathrm{ZnO}$ single crystal is unity. According to the ratio curves calculated by Makkonen et al., ${ }^{37}$ the ratio at $\mathrm{p}_{\mathrm{L}}=0$ of $\mathrm{V}_{\mathrm{Zn}}$ is about 1.08 . As shown in Fig. 11, the ratios at $\mathrm{p}_{\mathrm{L}}=0$ are 1.16, 1.22, and
1.09 for the $\mathrm{ZnO}: \mathrm{Sb}(2 \%)$ as-grown, annealed at 750 and $900^{\circ} \mathrm{C}$. The S-parameters of the corresponding samples also follow the same trend versus the annealing temperature (as shown in Fig. 10). For the as-grown $\mathrm{ZnO}: \mathrm{Sb}$ sample, the ratio at $\mathrm{p}_{\mathrm{L}}=0$ is 1.16 which is larger than that of the $\mathrm{V}_{\mathrm{Zn}}$ / $\mathrm{V}_{\mathrm{Zn}} \mathrm{V}_{\mathrm{O}}$ but smaller than the pure $\mathrm{Sb}$, indicating that both $\mathrm{V}_{\mathrm{Zn}}$ and $\mathrm{Sb}_{\mathrm{Zn}}-2 \mathrm{~V}_{\mathrm{Zn}}$ coexist in the as-grown sample. As the annealing temperature increases to $750^{\circ} \mathrm{C}$, the ratio at $\mathrm{p}_{\mathrm{L}}=0$ increases to the maximum of 1.22 (and so does the Sparameter, as shown in Fig. 10), indicating the formation of the $\mathrm{Sb}_{\mathrm{Zn}}-2 \mathrm{~V}_{\mathrm{Zn}}$ shallow acceptor. Further increasing the annealing temperature $900^{\circ} \mathrm{C}$ decreases the ratio at $\mathrm{p}_{\mathrm{L}}=0$. This is due to the dissociation of the $\mathrm{Sb}_{\mathrm{Zn}}-2 \mathrm{~V}_{\mathrm{Zn}}$ into $\mathrm{Sb}_{\mathrm{Zn}}$ and $\mathrm{V}_{\mathrm{Zn}}$. As the ratio at $\mathrm{p}_{\mathrm{L}}=0$ of the $\mathrm{ZnO}$ :Sb sample upon annealing at $900^{\circ} \mathrm{C}$ is 1.09 , it is even lower than that of the as-grown $\mathrm{ZnO}: \mathrm{Sb}$ sample (similar trend for the $\mathrm{S}$-parameter in Fig. 10). This implies that a majority of the $S b_{Z n}-2 V_{Z n}$ has already been thermally dissociated to $\mathrm{V}_{\mathrm{Zn}}$ after annealing at $900^{\circ} \mathrm{C}$.

\section{CONCLUSION}

Sb-doped $\mathrm{ZnO}$ films were grown on sapphire using the PLD method. The as-grown samples were $\mathrm{n}^{+}$conducting for the $\mathrm{Sb}$ concentration not exceeding the threshold concentration $\left(\sim 8 \times 10^{20} \mathrm{~cm}^{-3}\right.$ for the present PLD grown samples at an oxygen pressure of $1.3 \mathrm{~Pa}$ ) and the relevant shallow donor was proposed to be the $\mathrm{Sb}_{\mathrm{Zn}}$ related defect. For high level $\mathrm{Sb}$ doping exceeding the threshold, $\mathrm{Sb}$ no longer occupied the $\mathrm{Zn}$ site but sat at the $\mathrm{O}$ site, and the resultant $\mathrm{Sb}_{\mathrm{O}}$ was the deep acceptor which would compensate for the free carrier. Annealing the $\mathrm{ZnO}: \mathrm{Sb}$ doped with a low $\mathrm{Sb}$ level lead to the formation of $\mathrm{Sb}_{\mathrm{Zn}}-2 \mathrm{~V}_{\mathrm{Zn}}$, which has been reported to be the shallow acceptor. The present result may explain why diverged results were obtained in studies of p-type doping of $\mathrm{ZnO}$ with $\mathrm{Sb}$, as the yielded Sb-related defects depended on the $\mathrm{Sb}$ concentration. It also implied that too high of a doping level of $\mathrm{Sb}$ was not good for effective p-type doping, because the $\mathrm{Sb}$ dopant occupied the O-site if the doping level exceeded the threshold of $\mathrm{Sb}_{\mathrm{O}}$ formation.

\section{ACKNOWLEDGMENTS}

This work was financially supported by the RGC GRF, HKSAR (Project No. 17302115), and the Guangzhou Science and Technology Project (2016201604030047).

${ }^{1}$ U. Ozgur, Y. I. Alivov, C. Liu, A. Teke, M. A. Reshchikov, S. Dogan, V. Avrutin, S. J. Cho, and H. Morkoc, J. Appl. Phys. 98, 041301 (2005).

${ }^{2}$ C. H. Park, S. B. Zhang, and S. H. Wei, Phys. Rev. B. 66, 073202 (2002).

${ }^{3}$ M. D. McCluskey and S. J. Jokela, J. Appl. Phys. 106, 071101 (2009).

${ }^{4}$ Y. J. Zeng, Z. Z. Ye, W. Z. Xu, D. Y. Li, J. G. Lu, L. P. Zhu, and B. H. Zhao, Appl. Phys. Lett. 88, 062107 (2006).

${ }^{5}$ C. G. Van de Walle, Phys. Rev. Lett. 85, 1012 (2000).

${ }^{6}$ D. C. Look, G. C. Farlow, P. Reunchan, S. Limpijumnong, S. B. Zhang, and K. Nordlund, Phys. Rev. Lett. 95, 225502 (2005).

${ }^{7}$ L. Liu, Z. Mei, A. Tang, A. Azarov, A. Kuznetsov, Q. K. Xue, and X. Du, Phys. Rev. B 93, 235305 (2016).

${ }^{8}$ M. G. Wardle, J. P. Goss, and P. R. Briddon, Phys. B 376, 731 (2006).

${ }^{9}$ X. B. Li, S. Limpijumnong, W. Q. Tian, H. B. Sun, and S. B. Zhang, Phys. Rev. B 78, 113203 (2008).

${ }^{10}$ D. C. Look, G. M. Renlund, R. H. Burgener, and J. R. Sizelove, Appl. Phys. Lett. 85, 5269 (2004). 
${ }^{11}$ S. K. Pandey, S. K. Pandey, V. Awasthi, A. Kumar, U. P. Deshpande, M. Gupta, and S. Mukherjee, J. Appl. Phys. 114, 163107 (2013).

${ }^{12}$ K. K. Kim, H. S. Kim, D. K. Hwang, J. H. Lim, and S. J. Park, Appl. Phys. Lett. 83, 63 (2003).

${ }^{13}$ S. K. Pandey, V. Awasthi, S. Verma, M. Gupta, and S. Mukherjee, Curr. Appl. Phys. 15, 479 (2015).

${ }^{14}$ S. Limijumnong, S. B. Zhang, S. H. Wei, and C. H. Park, Phys. Rev. Lett. 92, 155504 (2004).

${ }^{15}$ U. Wahl, E. Rita, J. G. Correia, A. C. Marques, E. Alves, and J. C. Soares, Phys. Rev. Lett. 95, 215503 (2005).

${ }^{16}$ U. Wahl, J. G. Correia, T. Mendonça, and S. Decoster, Appl. Phys. Lett. 94, 261901 (2009).

${ }^{17}$ F. X. Xiu, Z. Yang, L. J. Mandalapu, D. T. Zhao, J. L. Liu, and W. P. Beyermann, Appl. Phys. Lett. 87, 152101 (2005).

${ }^{18}$ J. C. Fan, C. Y. Zhu, S. Fung, Y. C. Zhong, K. S. Wong, Z. Xie, G. Brauer, W. Anwand, W. Skorupa, C. K. To, B. Yang, C. D. Beling, and S. Fung, J. Appl. Phys. 106, 073709 (2009).

${ }^{19}$ C. K. To, B. Yang, S. C. Su, C. C. Ling, C. D. Belilng, and S. Fung, J. Appl. Phys. 110, 113521 (2011).

${ }^{20}$ X. W. Sun, B. Ling, J. L. Zhao, S. T. Tan, Y. Yang, Y. Q. Shen, Z. L. Dong, and X. C. Li, Appl. Phys. Lett. 95, 133124 (2009).

${ }^{21}$ Y. R. Ryu, T. S. Lee, and H. W. White, Appl. Phys. Lett. 83, 87 (2003).

${ }^{22}$ A. Janotti and C. G. Van de Walle, Rep. Prog. Phys. 72, 126501 (2009).

${ }^{23}$ B. Puchala and D. Morgan, Phys. Rev. B 85, 195207 (2012).
${ }^{24}$ D. C. Look, K. D. Leedy, L. Vines, B. G. Svensson, A. Zubiaga, F. Tuomisto, D. R. Doutt, and L. J. Brillson, Phys. Rev. B 84, 115202 (2011).

${ }^{25}$ D. C. Look, K. D. Leedy, D. H. Tomich, and B. Bayraktaroglu, Appl. Phys. Lett. 96, 062102 (2010).

${ }^{26}$ D. Howarth and E. H. Sondheimer, Proc. R. Soc. A 219, 53 (1953).

${ }^{27}$ D. Rode, Semicond. Semimetals 10, 1 (1975).

${ }^{28}$ R. C. Scott, K. D. Leedy, B. Bayraktarouglu, D. C. Look, and Y. H. Zhang, Appl. Phys. Lett. 97, 072113 (2010).

${ }^{29}$ F. Tuomisto, V. Ranki, K. Saarinen, and D. C. Look, Phys. Rev. Lett. 91, 205502 (2003).

${ }^{30}$ H. Y. Liu, N. Izumskaya, V. Avrutin, Ü. Özgür, A. B. Yankovich, A. V. Kvit, P. M. Voyles, and H. Morkoç, J. Appl. Phys. 112, 033706 (2012).

${ }^{31}$ F. Tuomisto and I. Makkonen, Rev. Mod. Phys. 85, 1583 (2013).

${ }^{32} \mathrm{R}$. Krause-Rehburg and H. S. Leipner, Positron Annihilation in Semiconductors-Defects Defects (Springer, Berlin, 1999).

${ }^{33}$ S. K. Pandey, S. K. Pandey, V. Awasthi, M. Gupta, U. P. Deshpande, and S. Mukherjee, Appl Phys. Lett. 103, 072109 (2013).

${ }^{34}$ Y. W. Heo, S. J. Park, K. Ip, S. J. Pearton, and D. P. Norton, Appl. Phys. Lett. 83, 1128 (2003).

${ }^{35}$ Z. L. Wang, S. C. Su, M. Younas, F. C. C. Ling, W. Anwand, and A. Wagner, RSC Adv. 5, 12530 (2015).

${ }^{36}$ A. Teke, Ü. Özgür, S. Dogan, X. Gu, H. Morkoc, B. Nemeth, J. Nause, and H. O. Everitt, Phys. Rev. B 70, 195207 (2004).

${ }^{37}$ I. Makkonen, E. Korhonen, V. Prozheeva, and F. Tuomisto, J. Phys.: Condens. Matter 28, 224002 (2016). 